\title{
An Urban Architecture to Nurture People Affected by Alzheimer's Disease
}

\author{
by:
}

Amanda Lawrence

A thesis submitted to the Faculty of Graduate and Post Doctoral Affairs in partial fulfillment of the requirements for the degree of

Master of Architecture

Carleton University

Ottawa, Ontario

(c) 2012

Amanda Lawrence 
Library and Archives

Canada

Published Heritage

Branch

395 Wellington Street

Ottawa ON K1A ON4

Canada
Bibliothèque et

Archives Canada

Direction du

Patrimoine de l'édition

395 , rue Wellington

Ottawa ON K1A ON4

Canada
Your file Votre référence

ISBN: 978-0-494-91528-8

Our file Notre référence

ISBN: $978-0-494-91528-8$
NOTICE:

The author has granted a nonexclusive license allowing Library and Archives Canada to reproduce, publish, archive, preserve, conserve, communicate to the public by telecommunication or on the Internet, loan, distrbute and sell theses worldwide, for commercial or noncommercial purposes, in microform, paper, electronic and/or any other formats.

The author retains copyright ownership and moral rights in this thesis. Neither the thesis nor substantial extracts from it may be printed or otherwise reproduced without the author's permission.
AVIS:

L'auteur a accordé une licence non exclusive permettant à la Bibliothèque et Archives Canada de reproduire, publier, archiver, sauvegarder, conserver, transmettre au public par télécommunication ou par l'Internet, prêter, distribuer et vendre des thèses partout dans le monde, à des fins commerciales ou autres, sur support microforme, papier, électronique et/ou autres formats.

L'auteur conserve la propriété du droit d'auteur et des droits moraux qui protege cette thèse. $\mathrm{Ni}$ la thèse ni des extraits substantiels de celle-ci ne doivent être imprimés ou autrement reproduits sans son autorisation.
In compliance with the Canadian Privacy Act some supporting forms may have been removed from this thesis.

While these forms may be included in the document page count, their removal does not represent any loss of content from the thesis.
Conformément à la loi canadienne sur la protection de la vie privée, quelques formulaires secondaires ont été enlevés de cette thèse.

Bien que ces formulaires aient inclus dans la pagination, il n'y aura aucun contenu manquant. 


\section{Abstract}

As the baby boomers continue to age there is an increasing concern regarding the proper, dignified housing and care of this population. Studies suggest that an important element of successful aging is one's opportunity to live in a stable environment. 'This thesis will explore the adaptation of the built environment to diseases that cause failure of the human mind; it will focus on a design project which will address the aging population who has been diagnosed with Alzheimer's disease $(A D)$. This design proposal will allow people with mild to moderate $A D$ to live and stay in one place as they live out their final years. Furthermore, the proposal will address the importance of family and care-giver employees. This project will accomplish this aim through a designed physical environment, combining various components that have been shown to enhance and maintain the ability to function and improve quality of life for people with $A D .^{2}$ The proposed urban location is selected to offer the residents services and cultural stimulation. The design of effective, well-planned spaces and architecture aims to improve the quality of life for people with $A D$, associated employees, and visiting family members.

\footnotetext{
'Nancy Hooyman, and Asuman Kiyak, Social Gerontology. A Multidisciplinary Perspective, (Boston: Alyn and Bacon inc., 1999).

${ }^{2}$ Wilbert Gesler, Healing Places, (New York: Rowman \& Littlefield Publishers, Inc., 2003), 11.
} 


\section{Acknowledgements}

First and foremost, I would like to thank my thesis advisor, Paul Kariouk, who has generously provided support in numerous ways; offered a great quantity of insight, guidance and encouragement throughout the development of this thesis.

Also, I am grateful for the help of close friends, family. caregivers, and health care employees, who have shared with me their experiences and battles with Alzheimer's disease. Without them this thesis would not have been possible.

I would also like to extend a special thank you to all my friends, colleagues, and family members who have been supportive and helpful, in transpiring my academic career into an enjoyable, gratifying experience.

And of course, last but certainly not least, I owe my deepest gratitude to my loving parents, who have been a constant source of support, without whom I would not be where I am today.

This thesis is dedicated to those with Alzheimer's disease and their caregivers. 


\section{Table of Contents:}

ii

\section{Abstract \\ Introduction}

\section{Chapter 1: Alzheimer's Disease}

I. History

1.1 Symptoms

1.2 Stages

1.3 Psychological Issues: Culture and Discrimination

1.4 Past, Future and Present

1.5 Acceptance

\section{Chapter 2: Poetics of Architecture and Memory}

2. Memory

2.1 John Ruskin's and Nader Shabahangi's theory

2.2 Gabriel Radvansky's and John Zeisel's study

\section{Chapter 3: Design Strategies for People with AD}

\section{Living environments}

3.1 Mobility

3.2 Color [finishes, fabrics, textures]

3.3 Lighting

3.4 Sound

3.5 Material [senses]

3.6 Outdoor Spaces

\section{Chapter 4: Case Studies}

4. Alzheimer's Facility and Special Care Units

4.1 Case study 1

4.2 Case study 2

4.3 Case study 3

\section{Chapter 5: Urban Site Analysis}

5. Choosing a Site

5.1 LeBreton Flats

5.2 Carleton University

5.3 Notre Dame Cathedral and Initial Project Considerations

\section{Chapter 6: Design Proposal}

6. Program

6.1 Residences

6.2 AD Day Program

6.3 Family Suites

6.4 Circulation Element

6.5 Entertainment

6.6 Greenhouse

6.7 Wellness Center

6.8 Children's Daycare

6.9 Outdoor Spaces

\section{Concusions}

\section{Bibliography}




\section{Introduction:}

Memory is one of the unique aspects of human existence that individualizes and sets us apart from one another. It is human nature to learn from, share and think fondly of our memories. Unfortunately, with the continual progression of aging, millions of people are robbed of this precious gift. ${ }^{3}$ The Canadian Study of Health and Aging estimates one in ten Canadians aged sixty-five and older have some form of dementia, with $A D$ making up two-thirds of these cases. ${ }^{4}$ If progress is not made within this field, fifty-percent more Canadians could be facing $A D$ or a related dementia in just five years. ${ }^{5}$ This disease, caused by a failure in the brain, transforms the way a person experiences the world, spaces and people around them. Fortunately, improvements in medicine and technology have allowed people to live longer than ever before. Ironically, these advances have also enhanced the chances of the aging population to be

"Every five minutes someone in Canada develops Alzheimer's disease or other dementia today: this figure will increase to one every two minutes within a generation."

-Alzheimer's Society Canada

/htp://unwwalzheimer.ca/en/Research/AlzheimerSociery-Research-Program)

"We used to believe that mentally impaired people could not benefit from environmental design; now we have begun to recognize that they may be aided by design more than any other group and that our responsibilities to them do not end with 'special 'or secure units. We no longer focus on first impressions to the exclusion of other important issues like the significance of motion, socialization, and flow of activity.

- (KJiment. 2004)

(Building ype basics for senior living) diagnosed with $A D$. My familiarity with $A D$ has not only provided me with the inspiration to conduct this research, but has also allowed me to see the physical manifestations of this mental disease. These experiences have provided me with a deeper understanding of many of the common symptoms: sleeplessness, agitation, wandering, anxiety, and depression. Planned architectural spaces may dramatically reduce most of these physical symptoms. It is recognized that appropriate environments can

${ }^{3}$ Elizabeth Brawley, Designing for Alzheimer's disease. , (New Jersey. John Wiley \& Sons, Inc., 1997I, xiii.

${ }^{4}$ Aglukkaq, Leona. Minister of Health: Government of Canada." A/zheimer's Awareness Month. (2011): 2.

5 ('Rising Tide: The Impact of Dementia on Canada' 12/01/11) 
motivate mobility and influence one's quality of life and health. ${ }^{6}$ Increased knowledge of individuals with $A D$ and the existing care facilities available for this population has led to a better understanding of suitable physical environments. The proposed built environment will benefit those who suffer from $A D$, their families and care-givers.

${ }^{6}$ Elizabeth Brawley, Designing for Akheimer's disease, (New Jersey: John Wiley \& Sons, Inc.. 1997). XV 


\section{Chapter 1: Alzheimer's Disease.}

\section{History}

HENIAT BOAN NATEMER EON

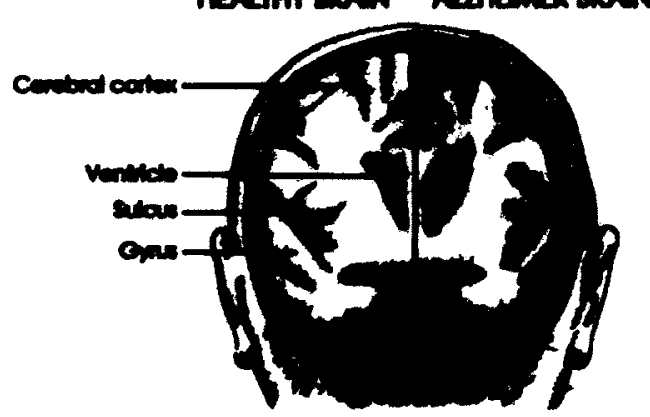

(Figure 1 mustration comparing a healthy brain (on the left) to a person who has $A D$ (on the right)

Brain shrinkage is associated with loss of neurons in the cerebral cortex and subcortical structures. This results in the decrease in amounts of certain neurotransmitters which function as signal messengers.

-Dr. Donald R. McLachlan

(http//wnww.alzheimer.ca/en/About-

dementia/Alzheimer-s-disease/What-is-Alzheimer-sdisease]

Alzheimer's disease: Ispecific disease): Is a specific progressive brain disease that causes dementia. Alzheimer's destroys brain cells, which results in memory and thinking problems severe enough to affect work, hobbies and social life. The disease worsens over time into /: umvalzheimer.ca/en/Abour dementia; Alzhemer-s-disease What-is-Aizheimer-sdisease

Dementia /symptom/ is as general term that refers to many different diseases. (Symptom of a deterioration of intellectual abilities resulting from an unspecified disease or disorder of the brain) It is an impairment of memory and thinking that interferes with a person's ability to do things he/she normally would have been able to do. Some dementias are reversible. meaning that they can be treated and cured. Some are irreversible, meaning that there is no cure yet. (hero//mwwalzheimerca/en/Aboutdernertia/Dementias)
Throughout history, symptoms of Alzheimer's and dementia had always been recognized as part of a natural progression of aging. It was not recognized as a disease though, until 1907 when a German physician, Dr. Alois Alzheimer, preformed a brain autopsy on a deceased patient who died after years of severe cognitive disorders pertaining to memory, language, and social interaction. ${ }^{7}$ The brain autopsy discovered unusual deposits surrounding the nerve cells, creating senile plaques and neurofibrillary tangles. ${ }^{8} \quad$ Although Alzheimer's disease was first discovered in 1907, it was not until the 1970's that it was considered a major disease. Researchers believe it may be caused by a combination of factors such as aging. genetics and one's environment. Many medications are available to help treat and delay symptoms; however, they do not prevent the disorder. Even though scientists have considerably advanced in understanding potential genetic, and environmental factors since the disease's discovery, there is currently still no cure for Alzheimer's disease. ${ }^{10}$

7 Beth Reger. "Alzheimers Disease: A brief History and Avenues for current research.' Journal of Young Investigators, 6, no. 2 (2002).

http://mw.jyiorg/volumes/volumeb/issue2/features/reger.html laccessed Dec, 1920111 .

8 ("history of Alzheimer's Disease" 01/10/12)

${ }^{9}$ Stephen G. Post, The Moral Challenge of Alzheimer Disease, Ethical /ssues from Diagnosis to Dying, (Baltimore: The John Hopkins University Press, 2000), 66.

10 Donald McLachlan, Akzheimer a Canadian and Family Resource Guide, (Toronto: Myra Schiff and Lori Kociol, 1989). 9. 


\subsection{Symptoms}

Alzheimer's disease normally affects people over sixty-five. The disease is known to progress and affect different areas of the brain, resulting in various impaired abilities such as: changes in personality, mood swings, confusion, disturbances in short-term memory, problems with attention and spatial orientation, language difficulties, loss of body movement ability, loss of bodily function control and memory worsening that may ultimately become nonexistent." Usually once an ability is lost, it does not come back. However, research is now suggesting that some relearning may be possible since memories are not held in just one part of the brain. Experiences and memories are placed into various parts of the brain, the memory of a face in one part, colors in another and emotions related to experience in another. ${ }^{12}$ Introducing people with $A D$ to art, music and connecting them with their environment may help trigger those memories. ${ }^{13}$

\subsection{Stages}

$A D$ is typically found in people between the ages of sixty-five to eighty-five years old. However, "early onset" of Alzheimer's can manifest itself as early as age forty-five. The disease may range from five to twenty years and progresses more as the person grows older. ${ }^{14} \mathrm{~A}$ person diagnosed with $A D$ may experience

\footnotetext{
11 Lori Kociol, and Myra Schiff, Alzheimer: a Canadian Family Resource Guide, (Toronto: McGrawthill Ryerson, 1989). 3.

12 John Zeisel, I'm Soll here: A New Philosophy of Alzheimer's care, (New York: Penguin Group Ltd., 2009). 5.

13 Zeiset. 5.

14 ('History of Alzheimer's Disease' $01 / 10 / 12$ )
} 
three stages throughout the disease. These stages include: mild, moderate and severe AD.

The mild stage typically lasts two to four years, during this time a person becomes confused, less energetic, has poor judgement, experiences minor memory loss and mood swings, begins to avoid new places or people and may easily become apprehensive, frustrated or upset.

The moderate stage is the longest stage and may last between two to ten years. A person experiencing this stage may still perform simple tasks independently, however, will need assistance with more complicated actions. Memory continues to worsen, and the person may easily be disoriented and disconnected from reality. Oftentimes memory is confused with the past and present, which affects the person's ability to understand present situations. The person may also struggle with recognizing familiar faces.

The severe/final Alzheimer's stage typically last between one to three years. During this phase the person may lose their ability to speak, recognize people, control bodily functions, and memory may become nonexistent. The individual at this stage of the disease mostly sleeps, will require constant care, and is often referred to a nursing home or hospice for twenty-four hour surveillance and care. 
It is important to acknowledge that each person suffering from $A D$ is unique and will behave and react differently. As the disease progresses many researchers believe, "the patient reverts more and more to behavioral patterns developed earlier as a child, but which are no longer adequate for an adult."15 This is true, in that the person with $A D$ eventually progresses to the intellectual level of a young child who relies on complete adult supervision, as they cannot live or function on their own. Even though children and people with $A D$ have similarities, I am certainly not suggesting people with $A D$ are like children. This would be invalid since people with $A D$ have a life time full of experience and knowledge.

In terms of architecture it is important to design an environment that will provide comfort and complement various types of memories and experiences, as no two individual is alike. For the purpose of this design proposal I will focus on the first two stages of $A D$; the third stage is beyond architecture's capacity to be a healer.

\footnotetext{
15 Liduin Souren, and Emile Franssen, Broken Connections: Origin and course, the world of the patient, (Lisse: Taylor \& Francis, 1994), 59.
} 


\subsection{Psychological lssues: Culture and Discrimination}

Throughout history, Native Americans and Muslim groups have valued the importance of respect for their elders. These cultures in particular value the wisdom and experience that comes with living to an old age, believing it is the responsibility of the elder to pass down experiences and wisdom to the youth. ${ }^{16} \mathrm{In}$ contrast to Native Americans and Muslims, it can be argued that North American and European cultures appear to have long lost this trait. Western humanity is becoming seemingly unaware in terms of involvement with the elderly. As society continues to advance and be influenced by technology, television, media and science, many cultures, such as, North American, fail to appreciate the values and knowledge the aging population may provide. This may result in discrimination towards the elderly, specifically those with $A D$, who are often considered burdens Furthermore, today's society often believes that anyone who does not speak, think or remember as quickly and efficiently as the majority must be abnormal or diseased. ${ }^{17}$ The question arises: can architecture counter this progressive cultural discrimination against the elderly, perhaps by recreating, less institutional environments for those who are suffering from $A D$.

\footnotetext{
16 6 Jenny Tyndale, "Respect for the Elderly," Wall Street Joumal (2005). Hut://wsjclassroom.com/archive/05may/related_05may_teacher_elderly.hum (accessed January 12, 2011).

17 John Zeisel, I'm Soill here: A New Philosophy of Alzheimer's care, INew York. Penguin Group Ltd., 2009), 10.
} 


\subsection{Past, Future and Present}

John Zeisel author of the novel I'm Still Here describes people with Alzheimer 's as follows;

The way a person sees Alzheimer's today is that a person is almost totally lost once he or she is diagnosed, lost both to themselves and to those who love them. It is seen as an Alzheimer's 'sentence.' But this just isn't so. Throughout the more than decade-tong progress of the disease, the person is crying out, "I'm still here'. We all need to start hearing that cry before it fades away completely. ${ }^{18}$

Unfortunately, society assumes that people with $A D$ have no future. As previously mentioned, the condition may last anywhere from five to twenty years, a period that undeniably represents a future. However, today's society does not seem to comprehend what kind of future one with AD may have if he/she cannot always remember his/her past, people, or surroundings. This judgement presumes that memories have vanished, which, they have not: they are just gradually more out of reach especially when without assistance. ${ }^{19}$ The future for a person with $A D$ is often based on present moments and building new relationships and a new quality of life with reference to the past. Caregivers and family members must come to terms with the fact that a person suffering from $A D$ is a new person in regards to the former he/she always was but that he/she is not necessarily that person anymore. ${ }^{20}$ Therefore, it is inappropriate to presume the same relationship. Even though the person with AD may not always be able to remember details, such as names or faces, he/she can still communicate expression through body language.

\footnotetext{
18 John Zeisel, I'm Still here: A New Philosophy of Azzheimer's care, (New York: Penguin Group Ltd., 20091. 7.

19 Zeiset, 10.

${ }^{20}$ Zeiset, 9.
} 
"Love is a universal language understood far into the illness, with or without words." 21

\subsection{Acceptance}

In order to fully accept people living with $A D$ as opposed to ill patients, we must learn to be grateful for their capabilities as well as their losses. ${ }^{22}$ The way the illness affects the brain leaves most people with $A D$ remarkably insightful, progressively more creative, and highly emotionally intelligent for years. ${ }^{23}$ It is up to family members and care givers to determine what remaining capabilities are easily reached, such as reading, knitting, playing music or gardening, and to encourage these capabilities. This will allow the person with $A D$ to maintain his/her dignity and independence for as long as possible. Furthermore, people with $A D$ often appreciate what most people take for granted, such as walking through a park or simply observing the environment. They often have fascinating things to say and express themselves through integrity and imagination. Therefore, as stated by Nader Robert Shabahangi,

Society must learn to understand our human differences no longer as a phenomenon to be normalized or cured but rather as an opportunity to extend our awareness of our amazing diversity and purposes. ${ }^{24}$

People who have AD should be given the opportunity

"I am really only beginning to enjoy the now of life, something that completely passed me by before. So, all in all, I would describe Alzheimer's as a new stage in a wonderful life, no less challenging or interesting than all the earlier stages."

- Cathleen McBride

('m Sill Here, by John Zeisell)
21 John Zeisel, I'm Still here: A New Philosophy of Alzheimer's care, (New York: Penguin Group Ltd., 20091,22.

22 Donald MCKay, Sanctuary. a care centre for patients with Alzheimer disease, (Waterloo: University of Waterloo Press. 1988), 104

23 Zeisel, 3.

24 Nader Shabahangi. The Poetics of Aging and Dementia, "Joumal of Humanistic Psychology April 2010, 50 (2009) 


\section{Institutionalized:}

1. To make into, treat as, or give the character of an institution

2. To make part of a structured and usually well-established system

3. To place or confine in an institution, especially one for the care of mental illness, alcoholism, etc.

(ntrp://dictionary.reference.com/browse/Institutionaliz ed?s-t)

\section{Memory:}

noun

1. The mental capacity or faculty of retaining and reviving facts, events, impressions, etc., or of recalling or recognizing previous experiences.

2. The act or fact of retaining and recalling impressions, facts, etc: remembrance; recollection: to draw from memory.

3. A mental impression retained; a recollection: one's earliest memories. (hitp://dictionany reference.com/browse/memory?s-t) to persist to have an active future, without the feeling of being institutionalized or concealed from society. If society learns to be positive and optimistic with regards to $A D$, people who have the illness will react more positively.

\section{Chapter 2: Poetics of Memory and Architecture}

\section{Mernory}

Memory is an organism's ability to store, retain. and recall information and experiences.

There are many different types of memory: some of our memories are long term, while others are not, some are based on our senses while others are based on actions and behaviours.

Examining the relationship between architecture and memory could help in the design of a suitable healthcare home for people with dementia and AD. Appropriately designed environments could help trigger enjoyable past experiences for people with $A D$. For instance, the smell or sense of a space may bring comfort to someone with $A D$ or remind them of a pleasant past experience, whether they are conscious of it or not. Inevitably, this will prove to be a challenge since everyone has different memories and life experiences; thus, the design must offer various experiences to accommodate all. 


\section{Remember.}

verb (used with object)

1. To recall to the mind by an act or effort of memory, think of again: I'll try to remember the exact date.

2. To retain in the memory; keep in mind; remain aware of: Remember your appointment with the dentist.

3. To have (something) come into the mind again: I just remembered that it's your birthday today.

verb (used without object)

1. To possess or exercise the faculty of memory.

2. To have recollection /sometimes followed by off. The old man remembers of his youth.

(hnp://dictionary.reference.com/browse/re-member)

\subsection{John Ruskin's and Nader Shabahangi's theory.}

In the book Memory and Architecture, the architectural theorist John Ruskin describes architecture as society's primary port of memory, more reliable and genuine than any text. We may live without her", Ruskin makes a reference to architecture when stating, "And worship without her, but we cannot remember without her". Ruskin believes memory may truly be the sixth lamp of architecture. ${ }^{25}$ He believes architecture therefore has the ability to transform words, needs and desires into space. Author Eleni Bastea of Memory and Architecture agrees and believes that architecture:

...can capture fleeting or insistent memories into tangible, buildable or unbuildable forms. Architecture provides the stage on which we can enact our lives. Memory, however, creates a special relationship with space, holding on to the essence of it, the best and the worst, letting the rest of the details fade into gray. ${ }^{26}$

It is fascinating to see how architecture or architectural elements may affect one's memory, or perhaps may recreate a feeling of excitement, unease or fear. When designing a building, whether consciously or not, one will always refer to what one is familiar with: for instance, the reminiscence of a picturesque garden, a restful window sill, a generous stair or a narrow corridor or dark basement. We remember and discover spaces because we spend the majority of our life in them, and they in some ways become a part of

\footnotetext{
${ }^{25}$ Mieke Bal, Lynne Cooke, Beatriz Colomina, Jerny Gorovoy, Christiane Temisse, Danielle Tilkin, and Josef Heffenstein, Louise Bourgeois: Mernory and Architectre, (Actar/Museo Nacional Centro de Arte Reina Sofia and Aldeasa, 200). 169

${ }^{26}$ Eleni Bastea, Memory and Architecture, (New Mexico: The University of New Mexico Press, 20041, 1.
} 
us and often influence the way we design. ${ }^{27} A$ further analysis of memory and space is proposed by Nader Shabahangi, in his novel Poetics of Aging and Dementia. Shabahangi believes that everyone has his or her own distinct perception of space and that people have as many realities as they have individual perceptions. ${ }^{28}$ Therefore, the same space is interpreted entirely different by each individual. Shabangin states:

This awareness that perception equals each person's reality has fundamental implications, one of which states that there does not exist one universal spatial truth. We humans individually create our own truths, truths that are ever changing, shifting, and transforming with time, with our learning, experiencing and growing. ${ }^{29}$

This can be even more true for people with dementia or $A D$ since they progress to live in their own fictional world. It is possible that people within the third stage of $A D$ may not even be aware of their physical surroundings, and may live exclusively through their imagination. However, in cases of people in less severe stages of the disease architecture can help nurture their memories. Therefore, it is important that the proposed design provides diverse environments to allow residents to explore their minds and find which setting will accommodate them best.

\footnotetext{
27 Mieke Bal, Lynne Cooke, Beatriz Colomina, Jerry Gorovoy, Christiane Terrisse, Danielle Tilkin, and Josef Helfenstein, Louise Bourgeois: Memory and Architectre, (Actar/Museo Nacional Centro de Arte Reina Sofia and Aldeasa, 2001.3

${ }^{28}$ Nader Shabahangi, The Poetics of Aging and Dementia, "Journal of Humanistic Psychology April 2010, 50 (2009)

29 Shabahangi, 2009
} 


\subsection{Gabriel Radvansky's and John Zeisel's study.}

In a recent study published in the Ouarterly Journal of Experimental Psychology, researcher Gabriel Radvansky explores how spatial organization can influence the mental narratives we build to learn, preserve and apply information. ${ }^{30}$ Radvansky questions:

Have you ever rushed across your house to get something from another room, but by the time you got there you completely forgot why you were there? This might be a trivial question for architects, but it might have more to do with architecture than you might think. ${ }^{31}$

The study demonstrates that memory appears to be affected by how many doorways and rooms one passes through. Radvansky's research describes this as the 'location updating effect'. Conversely, where there is only one event, such as a single open room linked with a particular goal or activity, it is much easier to remember because there would be no need to update the location. Although one open, single room may allow one to easily focus and remember where they are, it does not necessarily mean architects should design large open plans with minimal thresholds. Radvansky states:

Design should be based on the space's program. Research suggests that setting aside specific rooms for specific tasks may be more beneficial than a large open plan that incorporates many different tasks. The divisions help keep the organization of our mental narratives more stable and easier to remember. If we require collaboration, then open-plans seem to be more beneficial for memory than

\footnotetext{
30 Christopher Henry, "Can Design influence memory?" Arch Daily (2011). hut://uww.archdaily.com/184725/can-designinfluence-memory/ laccessed January 20,20111.

(Henry 2011 )
} 
individualized room, and vice versa for specific tasks. $^{32}$

As further discussed in I'm Still Here by John Zeisel, this concept also applies to people with AD. Zeisel discusses the importance of encouraging people with $A D$ to walk rather than aimlessly wander. Paths with clear destination points, such as an activity room, would encourage the resident to walk over and participate. ${ }^{33}$ Therefore, the sense of a space as well as its aesthetics should be different based on the space's intended purpose. With a better understanding of mental narratives architects and designers may be able to design memorable spaces, which will encourage independence and comfort to people living with dementia and $A D$.

"If the house is the first universe for its young children, the first cosmos, how does its space shape all subsequent knowledge of other space, of any larger cosmos? is that house "a group of organic habits" or even something deeper, the shelter of the imagination itself?"

- Gaston Bachelard

the Poetics of Space)

${ }^{32}$ Christopher Henry, "Can Design influence memory?: Arch Daily (20111. hitp://mww.archdaily.com/184725/can-design-influencememory/ laccessed January 20,20111.

33 John Zeisel, I'm Sall here: A New Philosophy of Alzheimer's care, (New York Penguin Group Ltd., 2009). 138. 


\section{Chapter 3: Design Strategies for People with} $A D$

\section{Ling environments}

Living environments influence our quality of life- including our health. If we are to recognize that the way we design has a significant impact on health and well-being, then we must have humane living environments that support independence and emphasize dignity and personal choice. Furthermore, these physical environments may help reduce residents" symptoms such as agitation, anxiety, aggression and apathy. The same environments, however, mean different things to different people. Depending on a person's background, culture, experience, age, and position in life, the same social and spatial conditions are perceived differently and will most likely stimulate different reactions. ${ }^{.34} \mathrm{~A}$ "healthy environment' however, offers a range of opportunities for people with $A D$ to participate in activities that will positively influence their lives. ${ }^{35}$ Design strategies to help create a healthy environment include: mobility, colour, lighting, sound, materials and landscape.

\footnotetext{
${ }^{34}$ Elizabeth Brawley, Designing for Alzheimer's disease. , (New Jersey. John Wiley \& Sons, Inc., 1997), 25

${ }^{35}$ Brawley, 25
} 


\subsection{Mobility}

Research has demonstrated that regular exercise and physical activity help delay the physical aspects of aging while supporting a healthy lifestyle. ${ }^{36}$ Daily physical activity will not only improve strength, endurance, and cardiovascular fitness but it can further help reduce anxiety, fear of falling, fatigue and even alleviate depression. John Zeisel believes mobility and the concept of 'way finding' could be improved by 'place knowing'. Most people with Dementia are aware of their surroundings only once they are there. Therefore, it is important to include 'way finding" features to help them locate their destination; being able to see an activity will encourage residents to walk over and participate. ${ }^{37}$ Features such as Dutch doors, low partition walls and interior windows are design strategies that encourage residents to see and partake in various activities. Furthermore, a safe environment with railings, flat walking surfaces, proper lighting and resting stops will help reduce a resident's fear of being mobile.

\subsection{Colour [finishes, fabrics, textures]}

It is believed that colour can help influence negative or positive reactions. Everyone interprets color differently often due to the aging eye and vision impairment.

Colour is a fundamental feature of environmental design. As stated in Elizabeth C. Brawley's book Design Innovations for Aging and Alzheimer's, "Color is linked to psychological, physiological and social reactions of

\footnotetext{
${ }^{36}$ Brawley. 95

${ }^{37}$ Bradford Perkins, David Hoglund, Douglas King. and Eric Cohen, Building spe basics for senior living (New Jersey. Wiley \& Sons, Inc., 2004), 69.
} 
human beings. as well as aesthetic and technical aspects of human- made environments." 38 There are valuable studies which have concluded that color can be interpreted or used to enhance a space. Colours may be affective not because of their hue but rather their shade and contrast to one another, which can help create a mood or sense of spaciousness. ${ }^{39}$ When choosing a color it is important to consider the users and purpose of the space. Everyone experiences colour, contrast and lighting differently; for instance, those with color deficits will not see as much contrast between two colors as someone who has perfect vision. In order to create effective colour contrasts for everyone to understand, colours must be more dramatic, making the light colour brighter and the darker colours even darker. Although choosing the "right" colors may be challenging, if done appropriately paint is a simple, affordable way to dramatically improve a space by making it more welcoming and serene. Many new retirement homes such as the Waterford Retirement Home in Kingston, ON, have appealing paint colours used on their ceilings to mimic nature. Works of art have been incorporated to create beautiful, well-lit spaces and can become a discussion piece; however, it is important to keep in mind that certain paintings may be confusing for someone with dementia who may not realise they are simply imitations. Patterns and color help prevent an institutional setting by recreating home-like settings; however, patterns with large motifs and strong contrasts may be challenging for the elderly with

(Figure 2) Waterford retirement home, Kingston Ontario.

\footnotetext{
${ }^{38}$ Elizabeth Brawley, Designing for Alzheimer's disease. (New Jersey. John Wikey \& Sons, Inc., 1997), 307.

39 Brawley. 114.
} 
balance, vision and depth issues. It is important to keep in mind that some colours may be exciting and vibrant to a youthful eye, but dull and boring to the aging eye. Therefore, carefully choosing the right colors and appropriate patterns will help create an enjoyable ambiance.

\subsection{Lighting}

The sun and natural light is an especially important element to consider when designing a healthcare center. Natural light provides many benefits such as energy efficiency, provides vitamin D, reduction of sleep disorders, reduces depression and can increase calcium levels. It is evident that sunlight is an important design feature which needs to efficiently be incorporated into the design to help improve the resident's quality of life. In Designing for Aging and Alzheimer's, Elizabeth Brawley reinforces the importance of light by stating: "It can and will make a greater difference in the success of a healthcare setting than any other single feature except the healthcare itself ${ }^{40}$ Oftentimes lighting for a healthcare facility can be quite challenging. To present a healthy environment it is common for a main reception area to provide a grand open space with large windows and to maximize light penetration. However, the corridors often remain institutional and artificially lit. Common strategies to help bring in and control light include overhangs, awnings, windows, light shelves, skylights. clerestories, saw tooth ceilings to eliminate glare, and floor to ceiling windows to allow daylight to enter as

\footnotetext{
${ }^{40}$ Elizabeth Brawley. Designing for Alzheimer's disease. ( New Jersey. John Wiley \& Sons, Inc., 1997), 54.
} 
far into the building as possible. When considering indoor artificial lighting it is important that lighting levels are consistent in each space with no dark corners or shadows, which can frighten people with dementia or $A D$. Lighting is one of the most valuable and important features to help improve the residents' visitors' and employees' quality of life.

\subsection{Sounds}

\section{According to statistics Canada:}

Hearing loss is the fastest growing, and one of the most prevalent, chronic conditions facing Canadians today. While hearing loss has many causes, age-related and noise-induced hearing loss are the two most common types...more than one million adults across the country reported having a hearing-related disability ${ }^{41}$

Noise can create unbearable environments for people with $A D$ and hearing deficiency. Increased noise levels such as traffic, airplanes, voices, radio and $T V$ can increase anxiety, stress and blood pressure for people with $A D$. Similar to vision impairment, hearing loss can also diminish one's quality of life. It can also lead to social isolation, depression and decreased mobility. People with hearing impairment may adapt better in smaller, quiet environments, where hearing and communication is clearer and identifiable. Therefore, the proposed design will include sound-appropriate spaces by avoiding large areas where increased volume would be difficult to control. Elements such as windows, materials, doors, walls and ceilings with high performance sound-isolation materials will further help control sound.

${ }^{41}$ ('Statistics" 2010) 


\subsection{Material [senses]}

It is common for many architects and designers to design with one sense experience in mind: the visual. Human beings, however, have been given the gift to experience five senses: visual, touch, hearing. smell and taste. Creating spaces that may arouse various senses and memories can help one have a better understanding of a space. ${ }^{42}$ This is even more true for people with dementia and AD as they begin to have vision impairment and must learn to narrate spaces using other senses. It is important for designers and architects to see this as an opportunity to design spaces that will stimulate all senses. The texture, weight and smell of various materials used in the design should be carefully chosen to help create a memorable ambiance and allow residents to interact and become familiar with their surroundings. Fragrance of gardens, planters and cooking can help influence past recollections and water features can stimulate peaceful sounds. It is important to keep in mind though that too many sensory experiences will be overwhelming and confusing for someone with $A D$; therefore, an appropriate balance is essential.

\footnotetext{
${ }^{42}$ Wibert Gesler, Healing Places, (New York Rowman \& Littlefield Publishers, inc., 2003], 86.
} 


\subsection{Courtyard}

Over the past few years healthcare centers and retirement homes have come a long way in terms of providing better quality care for their residents. Unfortunately, these improvements are mostly focused on the building with inadequate attention to the exterior landscape. The landscape, therefore, is often an aesthetic afterthought which often serves no real purpose. These quickly assembled environments can be challenging for people with dementia and $A D$ to utilize and often provide them no benefit. Exterior spaces can be very therapeutic since they help stimulate sight, smell, touch and hearing. They help maintain a connection with the natural environment and can encourage mobility and social interactions for all age groups to enjoy. Making a connection to the physical outdoor environment in a design allows residents and employees to gain physical strength. fresh air, light exposure, and is known to reduce loneliness and anxiety. It is therefore important to pursue the tremendous potential nature has to offer when designing a building. Designing an effective landscape which will benefit and improve people with Alzheimer's quality of life must be carefully planned to take into consideration the residents' needs while also creating a safe environment.

When designing a landscape for those with dementia, items to consider are sun orientation, close restrooms, appropriate non-toxic plants, smooth and wide walking surfaces to accommodate for wheelchairs, places for pets and bird feeders, seating arrangements with varying sizes, handrails, and raised gardening beds with wheelchair alcoves. Many 
outdoor activities can stimulate residents' long term memory of previous household tasks such as mowing the lawn, bird watching, gardening, raking leaves or hanging clothes on a clothesline. It is important to include these activities and design elements into the landscape as therapeutic healing spaces. Gardening can revitalize ones' senses, help calm the mind and it can also be an enjoyable activity shared between, for example, a grandchild and grandfather/grandmother. Caring for a plant will allow the person with $A D$ to feel like they are a caregiver. These outdoor settings further provide a beautiful space for family and staff to view and enjoy as a community. 


\section{Retirement building:}

Luxurious Independent and assisted living accommodation for the aging population designed to make life simple. Offers various amenities and activities and includes all meals and cleaning services

Nursing home: (Subsidised assisted living) A private residential institution equipped to care for persons unable to look after themselves, as the aged or chronically ill. (htp://dictionary.reference.com/browse/nursingth ome?s-t)

\section{Chapter 4: Case Studies}

\section{Alzheimer's Facility and Special Care Units}

Unfortunately, it is difficult to locate inspiring architectural examples of Alzheimer's and dementia facilities in the world. Most of the facilities that exist in Canada, let alone Ontario, are long term care facilities that were built many years ago and would not satisfy today's regulations or current design philosophy. These facilities were designed with other illnesses and treatments in mind. People with dementia and AD. however, require a healthcare design that will meet there personal requirements. In an attempt to create a more comfortable home-like environment, Alzheimer's care centers are small in comparison to long term care facilities and occupants often range between fifteen to fifty people. Long, double-loaded corridors are being replaced with smaller neighbourhood clusters which include a dining room, living room, activity rooms and eight to twelve bedrooms, often branching off of a larger common space. ${ }^{43}$ Currently, many North American cities do not have AD specific facilities. In this case, people with $A D$ and dementia are often relocated into a retirement building or nursing homes. Due to increasing demand, retirement homes are beginning to incorporate a dedicated number of floors to accommodate people with dementia and AD. These "special" floors are architecturally the same as every other 'typical' independent living floor; therefore, they do not provide an appropriate environment for someone with $A D$. Special care units are for patients with mental needs such as people who suffer from

\footnotetext{
${ }^{43}$ Elizabeth Brawley, Designing for Abtheimer's disease. , (New Jersey. John Wiley \& Sons, Inc., 19971, 167.
} 
AD. They offer special activities, staff training and involve the residents' family members whenever possible as part of the program.

To help design an effective Alzheimer's care residence, three precedents were studied: The Alzheimer's Respite Centre located in Dublin, Ireland, The Glen Stor Dun lodge located in Cornwall, Ontario. and Woodside Place located in Oakmont, Pennsylvania. 


\subsection{Case Study 1}

Facility: Alzheimer's Respite Centre

Built 2009 (1392 m2)

Architect/s: Niall Mclaughlin

Location: Dublin, Ireland

Residence: Twenty-five day care people.

Advantages: Wide walkways to ease assisted ambulant / wheelchair access and designed to enable two caregivers to walk with a resident. Toilets are located within short distances of social areas and visible from beds in bedrooms, Lighting designed to minimize glare and shadow and to achieve even illumination throughout; Floor, skirting and walls are differentiated by use color and tone, Coloured walls and doors are introduced in key positions to aid orientation. The sloping site has been organized to provide a central fully accessible level area with level access to gardens and courts, the entrance is easy to find going in, but almost invisible once you are inside, Staff rest space is removed from the client area to allow full wind down and relaxation.

Disadvantages: The facility is not a permanent residence for $A D$; it is a day care center for 25 people, to allow caregivers a break.

Awards: AAl Special Award, 2010: Winner RIAI Award, 2010: Best Health \& Leisure Project RIBA European Award, 20 10: Winner

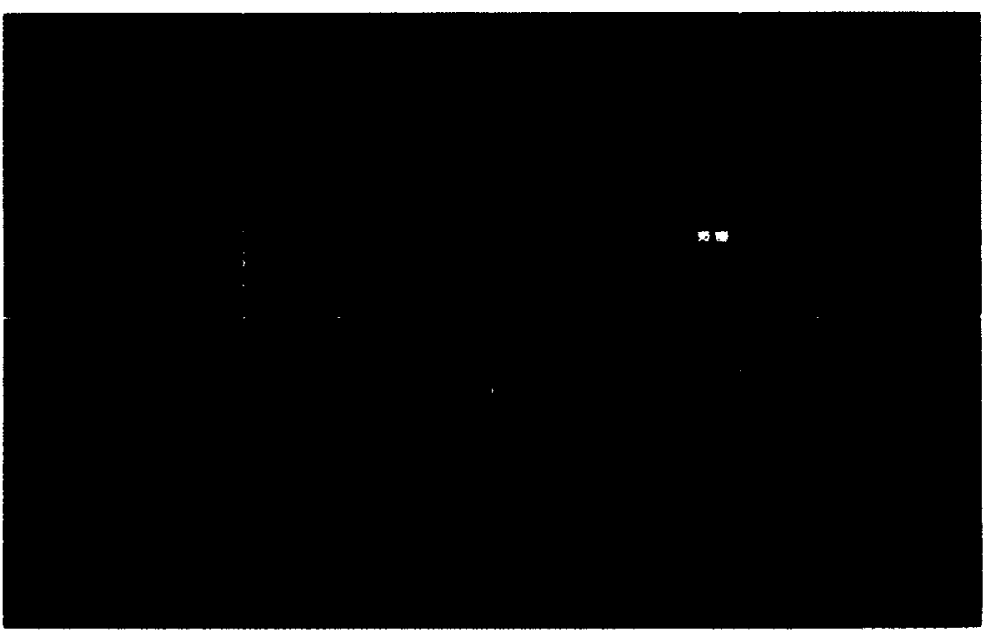

(Figure 3) Alzheimer's Respite Centre in Dublin, Ireland.

Alzheimer's Respite Centre by Niall Mclaughlin architects is located in Dublin, Ireland. The center is a day care facility for twenty-five people and includes eleven beds. It also includes offices for the Ireland 

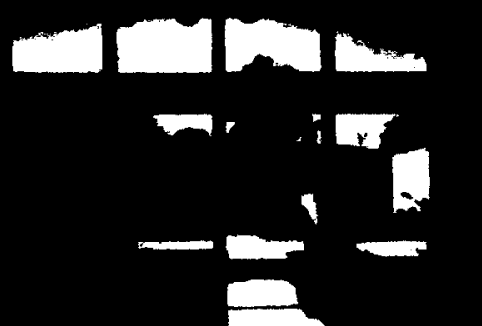

(Figure 4) Continuous view of exterior garden

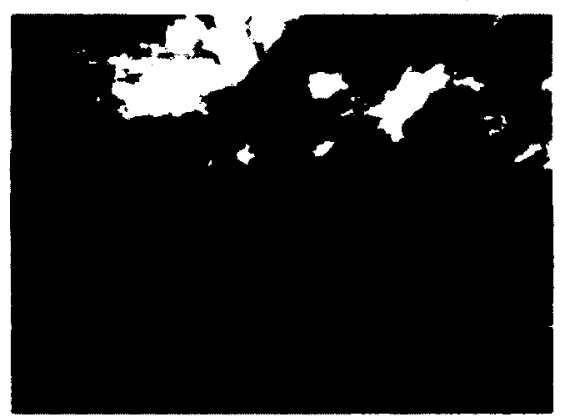

(Figure 5) Remaining $18^{\text {th }}$ Century walled kitchen

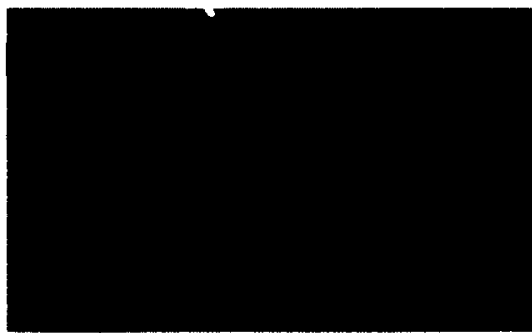

(Figure 6) One of many courtyards

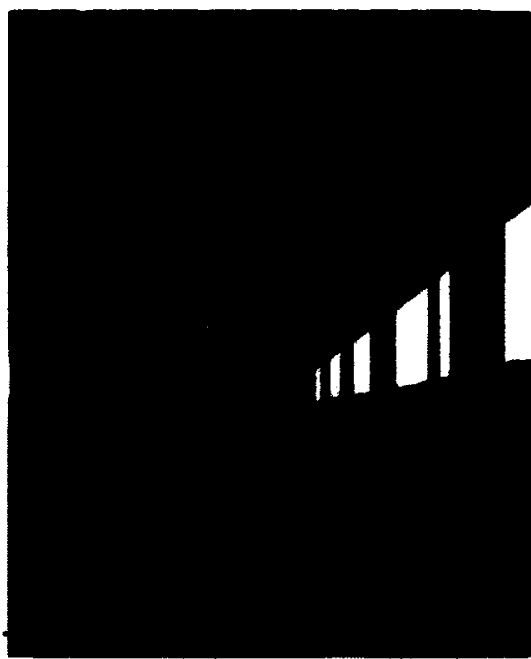

(Figure 7) Coloured bedroom doors and natural lighting from above
Alzheimer's society and is designed as a research example for future Alzheimer's care centers. The center is built within an existing $18^{\text {th }}$ century walled kitchen garden. (Figure 5) The design has been proven to enable some of the most vulnerable in society to live with dignity and joy as well as to provide them with a sense of belonging to a community. The project is based on the idea that memory allows us to remember where we are, based on how we got there. A building for people with $A D$ must therefore renew the sense of presence, and provide architectural elements that will help familiarize a person's location. ${ }^{44}$ This is accomplished through the use of color, light, social spaces, private spaces, materials, smells, orientation, courtyards and organization of movement.

This project provides well-planned environments; the continuous garden wall provides a protective enclosure without making the daycare residents feel a sense of imprisonment. Furthermore, the entrance is easy to locate from outside but difficult to find once one is inside. This allows the person with dementia to explore in complete freedom. Natural wandering loops are further incorporated in the plan through gardens and rooms avoiding claustrophobic, dark corridors and dead ends while always bringing the person with $A D$ back to the 'core': the design encourages mobility and independence. ${ }^{45}$ The building's design also focuses on the importance of color and lighting, for instance, the infrastructure is

\footnotetext{
${ }^{44}$ William Curtis, "Alzheimer's Respite Centre, Dublin, by Niall Mclaughlin Architects." The Architect's loumal, the home of British architecture (2011). http://wwwarchitectsjoumal.co.uk/buildings/alzheimers-respite-centre-dublinby-niallmclaughlin-architects/86 I 1 134.article (accessed January 10, 2011). (Curtis 2011)
} 
made of extending brick walls that support square wooden 'lanterns' which allow light to be brought deep into the building. ${ }^{46}$ (Figure 4 ) Lighting has also been designed to reduce glare and shadows. The building's walls and floors are visibly differentiated by use of color and contrast. Bedroom doors (figure 7) are also colour coded to distinguish bedrooms between toilets and non-accessible rooms. An additional successful feature is that the Alzheimer's Respite Center is strategically placed to constantly frame views of the gardens. Each garden is orientated in a different direction and intended to be experienced at various times of the day.

(Figure 8) Floor Plan of Alzheimer's Respite Centre
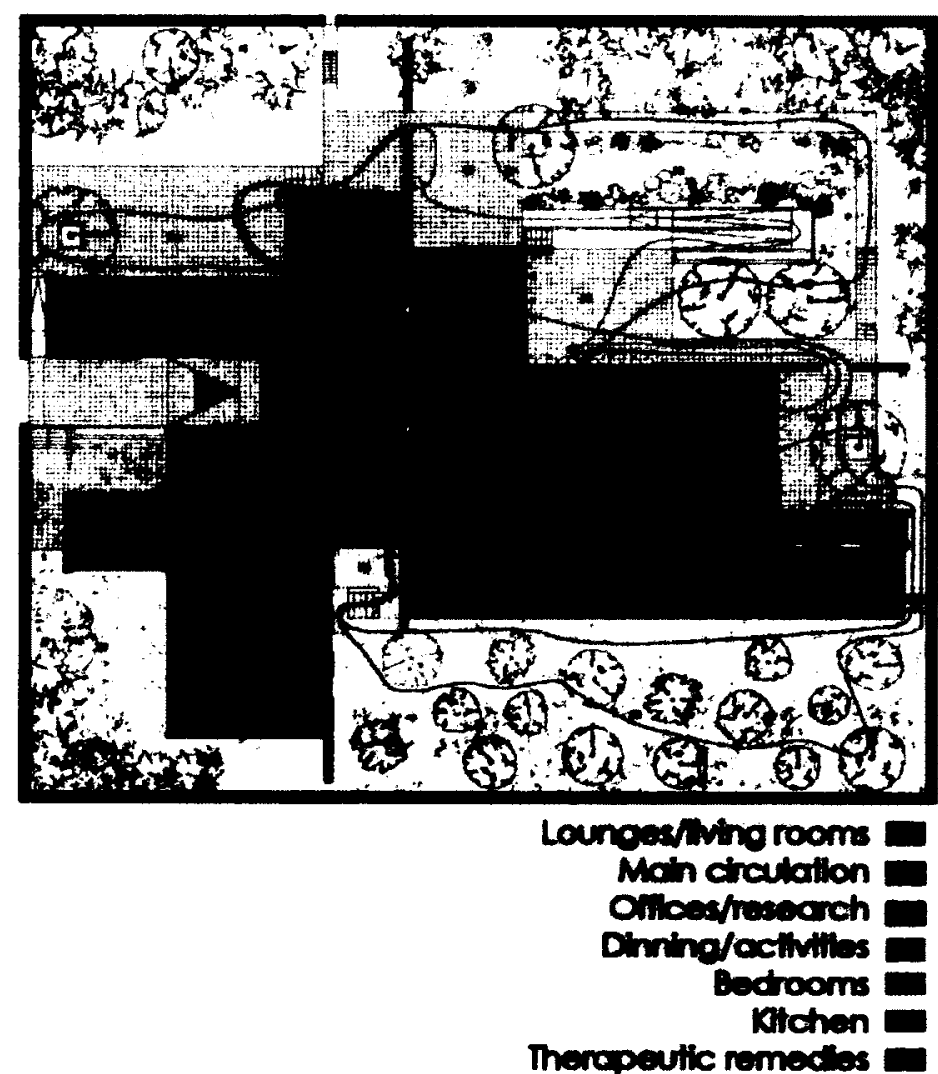

\footnotetext{
${ }^{46}$ William Curtis, "Alzheimer's Respite Centre, Dublin, by Niall McLaughlin Architects" The Architect's loumal, the home of British architecture (2011). http://unw.architectsjournal.co.uk/buildings/alzheimers-respite-centre-dublinby-niall-milaughlinarchitects/8611134.article (accessed January 10, 2011 ).
} 
As one moves through the building one is constantly provided with views of the gardens, which have a healing effect and further provide the daycare individual with a sense of familiarity and comfort.

Unfortunately, it is hard to fully understand limits to this care facility since a visit would be required to further analyse the designed environments and how they function. Although the Respite Center attempts to move away from the institutional look of a hospice, the perfectly manicured lawn and tall brick walls give a sense of emptiness and institutional feeling, which does not appear to be very soothing. The exterior ramped garden paths also appear to be very controlled, and may be challenging to use for someone in a wheelchair or with mobility issues.

Overall the Alzheimer's Respite Centre has many quality features that will be incorporated into the proposed design project. 


\subsection{Case Study 2}

Facility. Glen Stor Dun Lodge

Built 1994

Architect/s: N/A

Location: Cornwall, Ontario (along St. Lawrence River)

Residence: 132-bed Home for the Aged offering long term care.

Advantages: Memory photo feature wall, name on plaque, room entrances are clearly distinguished. large door to bedroom with open concept washroom, lounge space at each end of corridor. 'street market' on ground floor, outdoor raised garden beds and gazebo for shade.

Disadvantages: Dark spaces, long double sided corridor with artificial lighting, poor nurse station location, poorly designed tub and shower room, lack of animation and social interaction, front entrance is difficult to locate and does not provide any shelter. underutilized lounges along corridor, chapel does not include enough floor space for wheelchairs and beds.

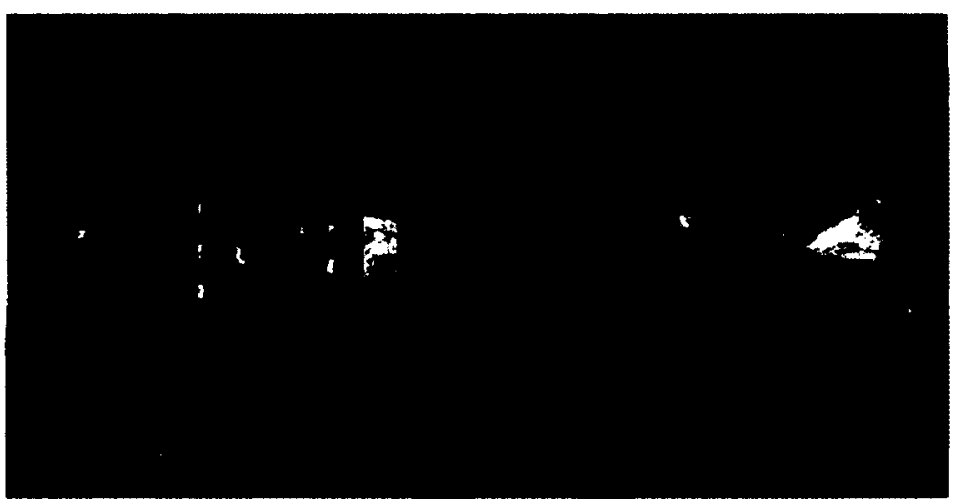

(Figure 9) Glen Stor Dun Lodge, Cornwall, ON

Main Street:

1. the principal thoroughfare, especially through the business district, in a small town.

2. the outlook, environment, or life of a small town.

3. the most prominent street of a town, usually where the principal shops and businesses are situatedordinary people in general 4. the most prominent street of a town, usually where the principal shops and businesses are situatedordinary people in general inttp://dictionary referencecom/browse/main+str eet) 


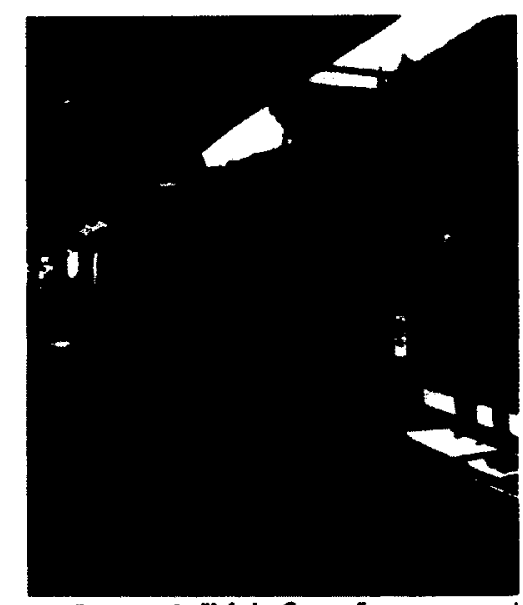

(Figure 10) "Main Street" on ground level at Glen Stor Dun Lodge

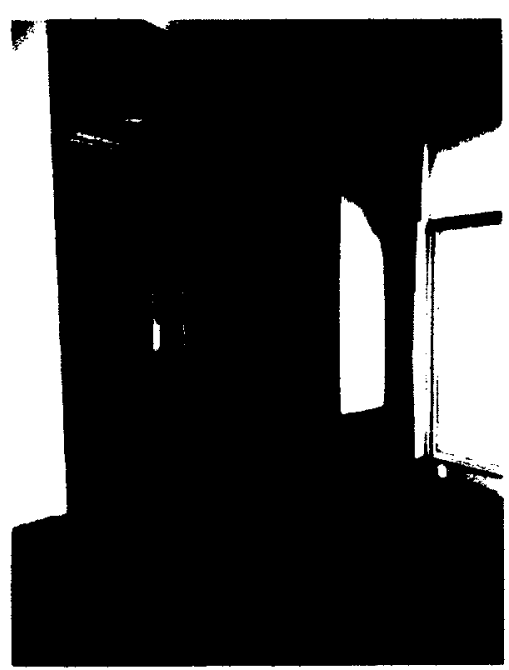

(Figure II) Ledge and memory photo frame

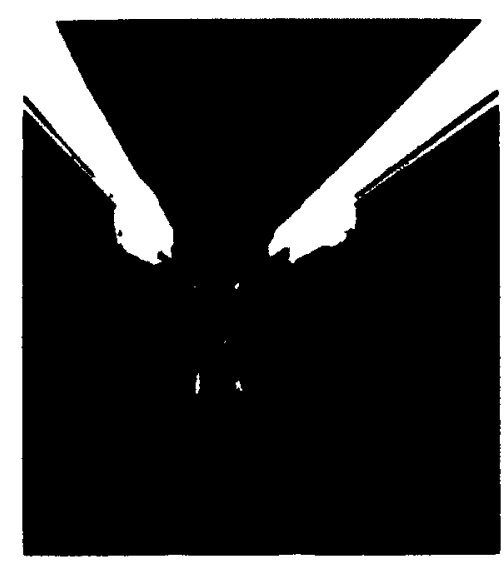

(Figure 12) Long double loaded corridor library, therapeutic room, chapel, cafeteria, lounge, fireplace, bank, reception, memorial/birthday wall and offices. The second, third and fourth floor are residential areas which include a total of a hundred and thirty-two beds. There are a hundred and eight private rooms and twelve semi-private rooms (two beds per room). ${ }^{48}$ Forty-four of these rooms are special care units for those with dementia and AD. There are two "Wards" per floor; each consists of twenty rooms, one bathing room, resident galleries, a nurse station, a dining room, an activity room, a lounge and personal care areas. The facility is also beautifully landscaped and includes a veranda, gazebo and raised vegetable beds for gardening. Glen Stor Dun Lodge has many valuable features which will be incorporated into the proposed design, for instance, each room entrance is embedded two feet into the wall creating a 'foyer' to each room and provides a space for a memory photo
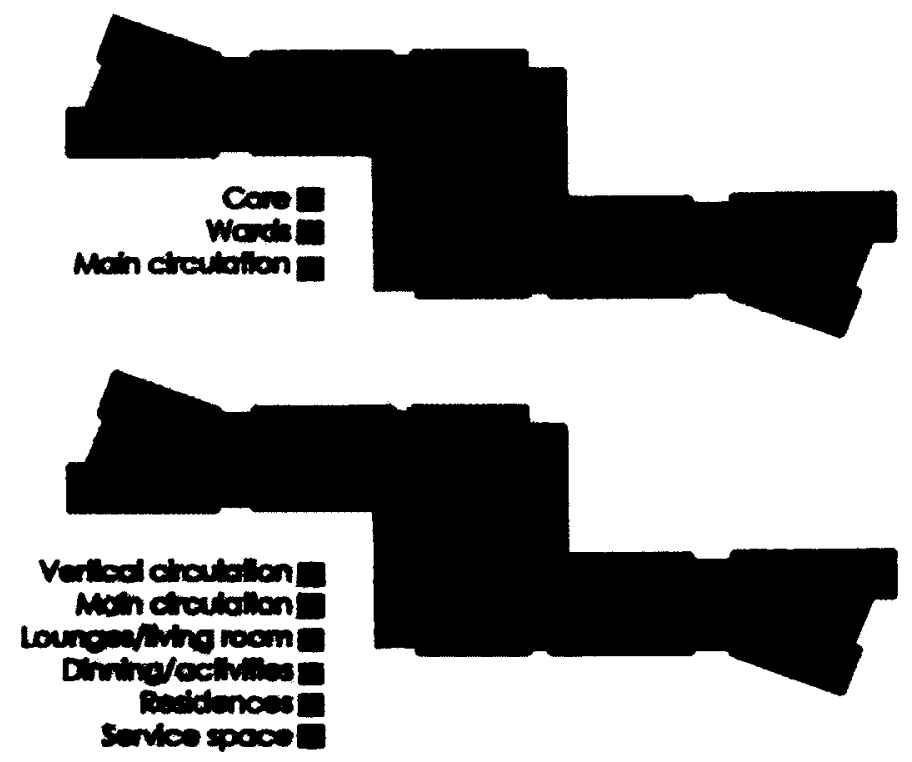

(Figure 13) Plan of Glen Stor Dun Lodge (demonstrates a lounge at the end of the corridor.

${ }^{48}$ ('About Glen Stor Dun Lodge' 2009) 
frame. This helps residents to distinguish their room from another person's room. Each room is very spacious and incorporates a large window allowing natural light to penetrate into the space. An additional positive feature is that the bedroom washrooms have an eight foot fold up wall which generally stays open cut can be closed if privacy is required. Although there is no continuous wandering 'loop', residents are never frustratingly faced with a dead end since both ends of the corridor are destination lounge areas, ([Figure 13) filled with natural light and views to the river.

A disadvantage with Glen Stor Dun Lodge is that the front entrance is a distanced walk from the parking lot. It is also difficult to locate and does not provide a sheltered drop off area. The proposed design will take this into consideration. 


\subsection{Case Study 3}

Facility. Woodside Place

Location: Oakmont, Pennsylvania

Residence: 36 beds

Awards: Three awards for being an outstanding model project: the Golden Seal Award from the National Council on Seniors' Housing at the National Association of Home Builders; the Innovation in Aging Award from the American Institute on Aging and the Association of American Homes for the Aged, and the Contemporary Long-Term Care Interiors Award.

Advantages: concept of smaller 'pods' branching off the larger main amenity space, distinct 'houses' suitable for each resident, Dutch doors, half open or closed, memory photo frame,

Disadvantages: Double sided corridor with dead end, steel fence around landscape, dreary landscape

\section{Woodside Place, located in Oakmont,} Pennsylvania, is a thirty-six bed residential Alzheimer's facility and is nationally one of the first of its kind. ${ }^{49}$ The long term care facility is separated into three, twelveresident 'houses'. Keeping the number of residents low

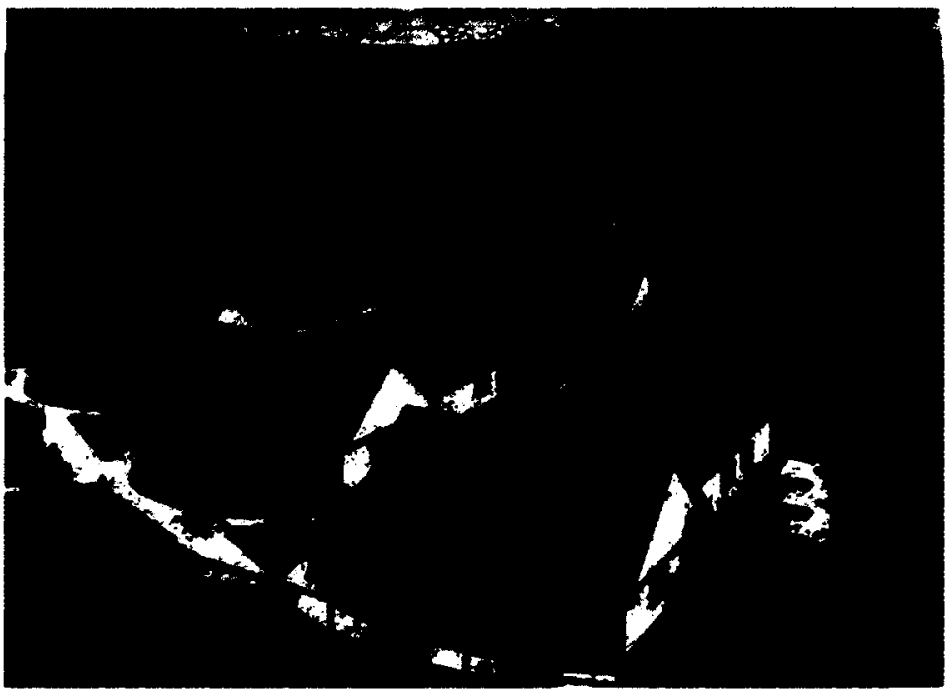

(Figure 14) Woodside Place, Oakmont, Pennsylvania

\footnotetext{
${ }^{49}$ Bradford Perkins, David Hoglund, Douglas King, and Eric Cohen, Bullding type basics for senior /iving, (New Jersey. Wiley \& Sons, Inc., 2004), 291.
} 
is calming and nonthreatening. ${ }^{50}$ The design aims to achieve a homelike setting that will physically and mentally support the various needs of people with AD, allowing them to move with meaning and explore freely. Each 'house' includes eight private bedrooms with private bathrooms and two double rooms. ${ }^{51}$ Each 'house' also provides a small kitchen for additional snacks or meals, a dining area, a bathing room and a lounge area. To avoid an institutional setting, nurse stations are incorporated into a work station counter as part of the kitchen layout of each house. Woodside Place uses three themes: star, tree and house which are symbols etched in a quilt design in order to help residents' memory and help them distinguish which house they belong to. Additional memory cues involve wallpaper borders which are chosen specifically to personalize a resident's room, for instance a farmer would have a farm scene wallpaper. The facility's core includes a shared kitchen (which acts as the hearth of the care center), a great room and a music room to provide places for social interaction. All the spaces are linked by a main circulation pathway which allows the residents to wander in a secure environment.

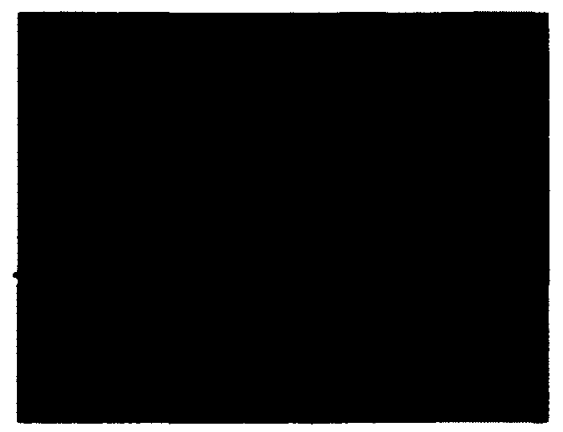

(Figure 15) Dutch door
${ }^{50}$ Wilbert Gester, Healing Places, (New York Rowman \& Littlefield Publishers, Inc., 2003), 95.

${ }^{51}$ Beth Deety, and Kristine Werlinich, Woodside Place: a personal care home for people with Alzheimer's disease," Aging (1992).

http:/findarticles.com/p/articles/mi_m lo00/is_n363-

64/ai_12519946/7tag-contentcoll (accessed January 24, 2012). 


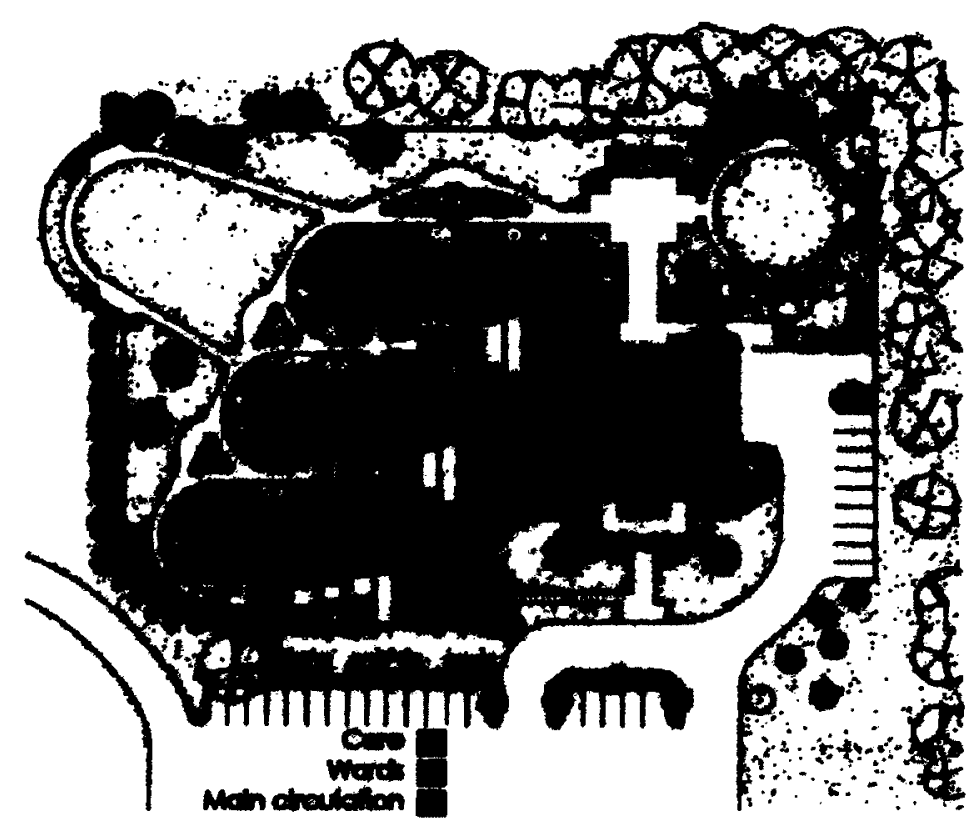

(Figure 16) Woodside Place, concept floor Plan

A disadvantage in the Woodside Place facility is that there still remains the extension of the doublesided corridor that leads to a dead end. (Figure 16) Furthermore the exterior courtyard is surrounded by a black fence, (Figure 15 ) which is intended to be concealed from residents but, may create a feeling of imprisonment. To avoid this, architecture and intelligent landscaped designs should be incorporated as a discrete shelter, in contrast to a harsh enclosure. In conclusion, the Woodside Place is a progressive concept model of 'pod' clusters branching off of a larger amenity space. The proposed design will incorporate the idea of 'pod' living. 


\section{Chapter 5: Urban Site analysis}

\section{Choosing a site}

People with $A D$ are capable of meaningful relationships, perceptions, feelings, and involvement in life. Therefore, an urban location is important, as it will allow residents to be a part of a community as opposed to being isolated away in a rural area. Three site locations were considered for this project and will be further described in the following pages. The locations include, in LeBreton Flats, on Carleton University's campus, and in the ByWard Market. The first two offered a picturesque setting, but did not require new infrastructure. These sites were not chosen because ultimately they were too isolated and lacked the essence of an urban environment. The third (selected) site is the location of a parking lot behind Notre Dame Cathedral, in the ByWard Market, between Sussex road and Parent Avenue. This site provides a greater design challenge in that its parameters within an urban fabric, present limitations based on the lot size and surrounding context. The proposed site will not only benefit the residents living with $A D$ as they will be in the center of an active urban location, but will also improve the value of the area by transforming the now dreary parking lot into an architectural and landscape space that will compliment the surrounding context. The new proposal will provide retail space, a daycare for children, a daycare for people with $A D$ and forty permanent rooms for people with dementia and $A D$. The design will also include a beautiful enclosed park. which will be available to the public during daylight hours, as an escape from a fast-paced urban setting. 


\subsection{LeBreton Flats}

LeBreton Flats is located in downtown Ottawa along the Ottawa River. In the $19^{\text {th }}$ century it was mostly industrial land that served the lumber mills on the nearby Chaudiere and Victoria Islands. ${ }^{52}$ It also incorporated housing for the owners and workers of the mill. In 1900 there was a great fire that destroyed the entire area, since then major development has transformed the area into newly developed mixed neighborhoods. A new Alzheimer's facility in this area would allow a dynamic variety of all ages to live in close proximity to one another. This would easily allow families of all generations to get together. The future development of the O-Train would allow families to travel across downtown Ottawa. Furthermore, the open landscape along the water would provide ample space for gardens, courtyards and water features, which will improve the current property and the

(Figure 17) Aerial plan of LeBreton Flats

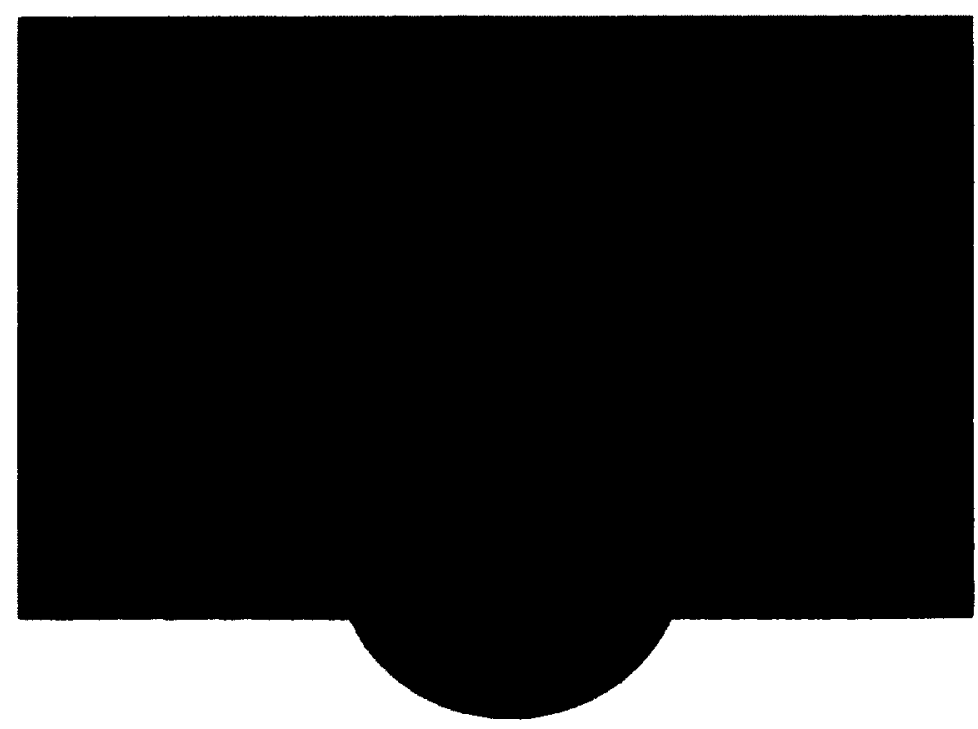

52 ('Cultural Heritage Value or Interest of Lower Lome Avenue" 2012) 
quality of life for those with $A D$. Even though this location proposes many advantages, similar to the Carleton site, it remains too secluded from the urban core and its location does not yet provide sufficient essential urban amenities such as, retail, restaurants, and theaters. 


\subsection{Carleton University}

Carleton University location was considered due to its beautiful setting along the Rideau Canal. The site provides ample space which would allow an Alzheimer's facility to stretch across on one level. Flowing water is known to be very therapeutic and soothing. Having an Alzheimer's center near a large water source would not only provide a picturesque setting but would also contribute to a healing atmosphere, a peaceful place to relax, and a place to reminisce about past memories. The challenge to this, however, is the requirement for increased surveillance along the water. This location would also allow Carleton students to volunteer at the care center, which can help 'normalize' the residents. The concept of the elderly and youth working together can be very therapeutic and encourage adolescents to value their elders, while allowing the elders to stay active by keeping up with the youngsters.

(Figure 18) Aerial view of Carleton University site

Normalize:

Verb

1. To make normal.

2. To become normal, resume a normal state

inttp//dictionary.reference.com/browse/Norm alize?s=t)

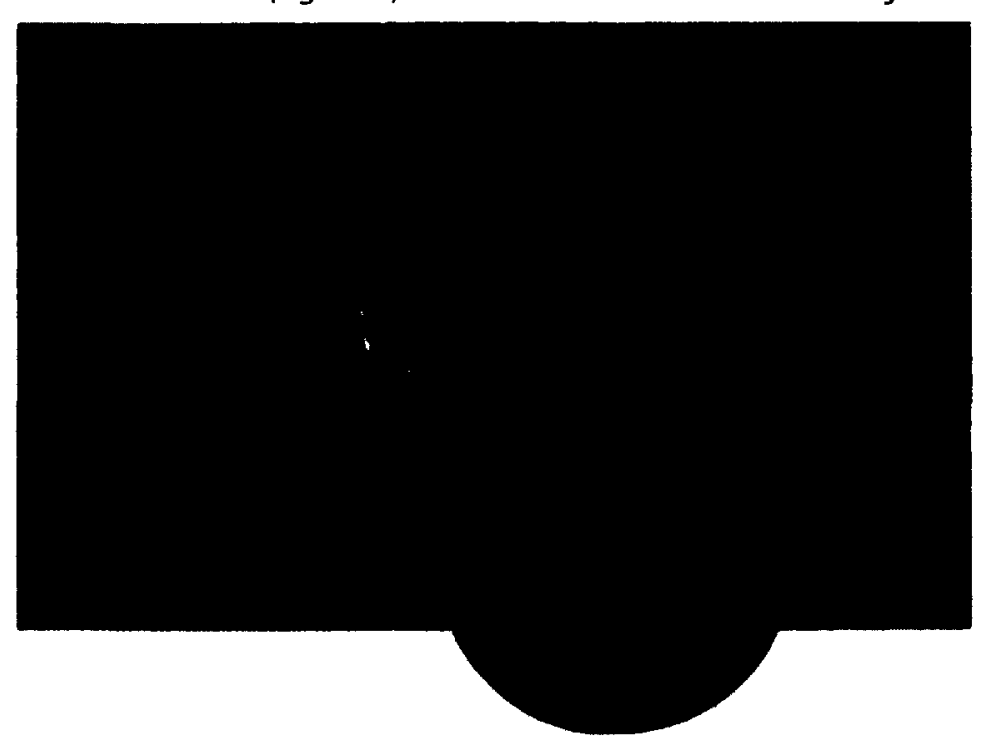


Therefore, they can both discover and learn from one another. If the demand for Alzheimer's facilities decreases, the facility could be transformed into student housing. Although this location poses intriguing possibilities, it is not realistic to assume that Carleton students would want to volunteer at the facility, especially since Carleton does not have a medical program; perhaps this arrangement would work better downtown near the University of Ottawa as they have an extensive health program. It would also be difficult to create a secure exterior environment without gating off the Canal and its view. Furthermore, the site is a bit isolated from the urban core, and would require a transportation method to get anywhere. This would discourage residents to leave the facility since the process would be too strenuous. Due to these factors I did not choose this location. 


\subsection{Notre Dame Cathedral and Initial Project}

\section{Considerations}

The Notre Dame Cathedral Basilica is located

on 375 Sussex Drive in the Lower Town area of

Ottawa's ByWard Market. The Neo-Gothic Roman

Catholic Church was completed in 1846 and in 1990 it was labelled a national historic site of Canada. ${ }^{53}$ Today it remains the largest and oldest Catholic Church in Ottawa. The proposed site is located directly behind

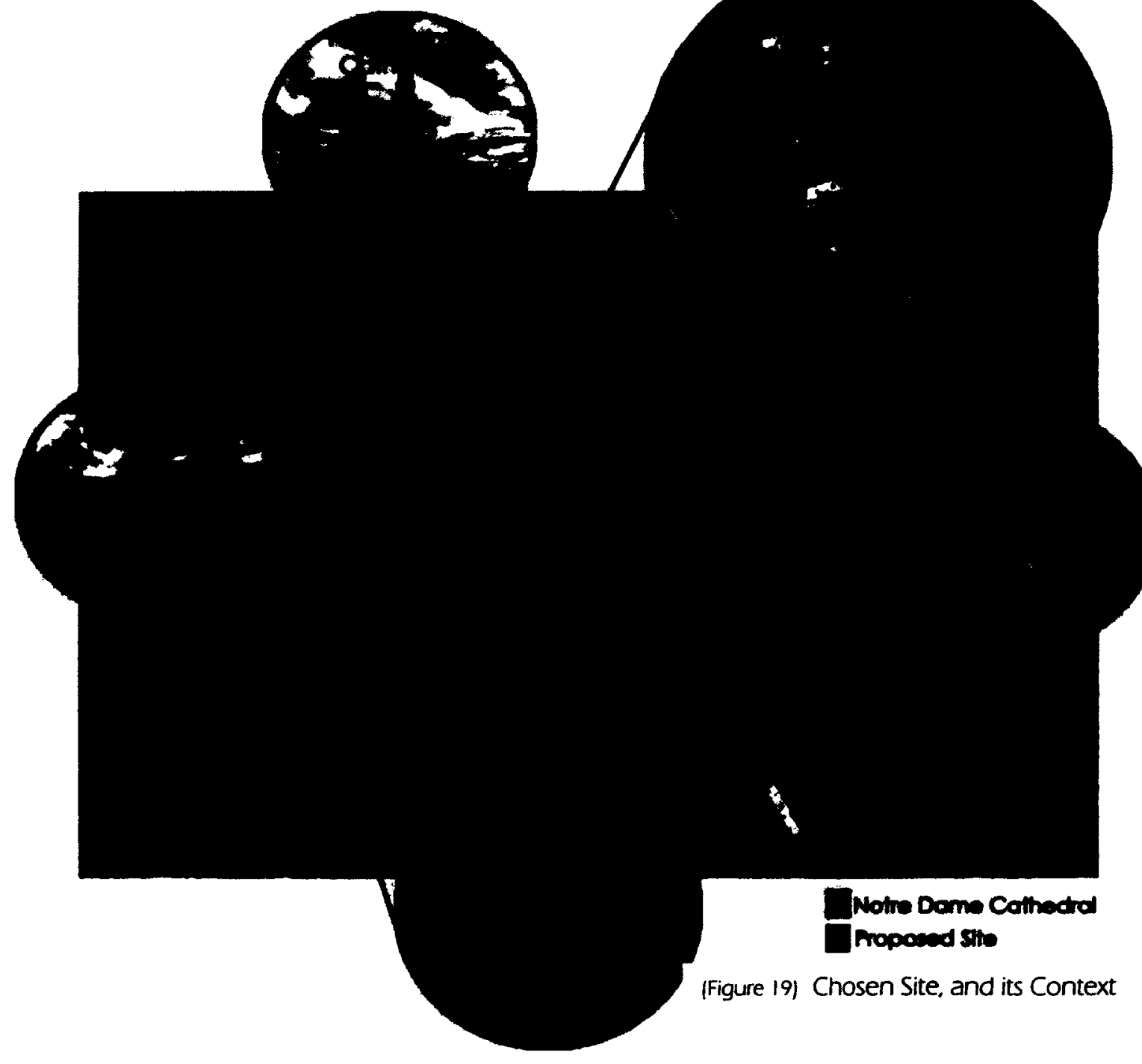

53 ("Notre-Dame Roman Catholic Basilica National Historic Site of Canada") 


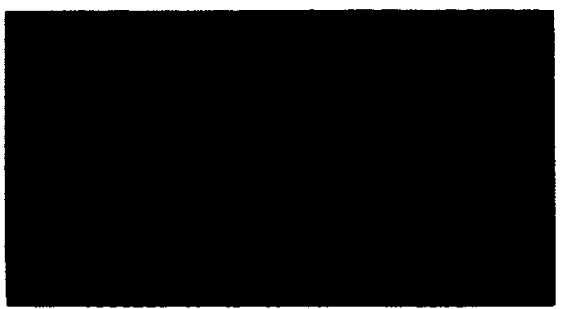

(Figure 20| View from St Patrick St. (Existing houses on the right)

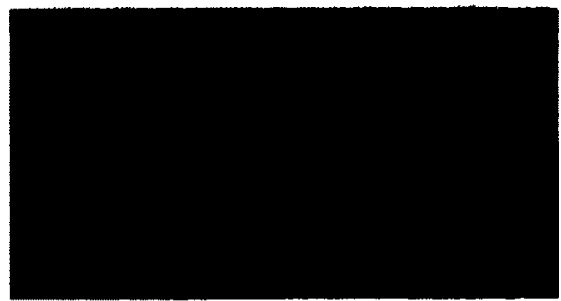

(Figure 21) Corner view from St. Patrick Street. And Parent Ave.

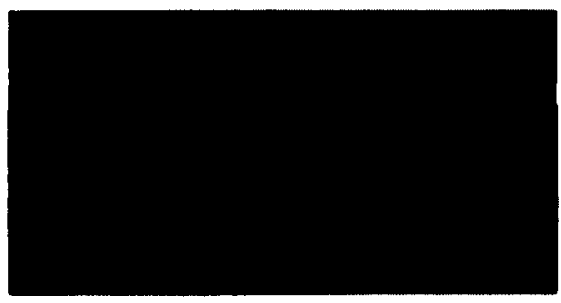

(Figure 22) Back view of site, from Parent Ave.

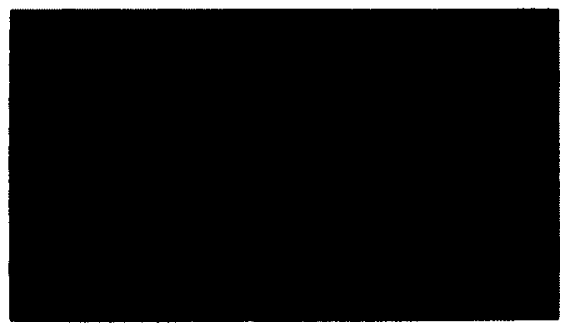

(Figure 23) View from Parent Ave. with church and National Art Gallery in the background the cathedral where there is currently a public parking lot used by commuters and visitors who come to visit the market. The ByWard Market location will allow the urban citizen who has memories of living in a city to remain living in the same type of setting in his/her final years. The best way to improve AD is to remain active; the Market offers many valuable amenities that will help 'normalize' and cater to an Alzheimer's care center. For example, it gives people the ability to walk to nearby parks, the Canal, the National Art Gallery, and Bytown museum, courtyards, Bytowne library. cinemas, boutiques, shops, restaurants, entertainment, food markets and more. Due to the site's many advantages this location was chosen for the proposed design. In order to accommodate the existing parking space, public parking can be placed below the proposed building, while the above area can be transformed into the needed facility which will include a garden that will offer the community a retreat from the busy city.

In order to design a successful garden it is important to analyze nearby existing courtyards, which essentially lead to the Notre Dame site. The analysis concluded that most of the existing courtyards are surrounded by buildings that are two to seven storeys tall and have a courtyard area between 11,900 sq.ft and 27,600 sq.ft. The proposed design will have a courtyard area of 18,000 sq.ft and will be surrouded by buildings three to five storeys tall. Based on the existing courtyard study I completed, the proposed courtyard is a more than appropriatly scaled to maximize facility use and give ample sunlight. The proposed garden will be one of the few landscaped 
gardens in the Market, since the existing courtyards are hard landscaped patios. 


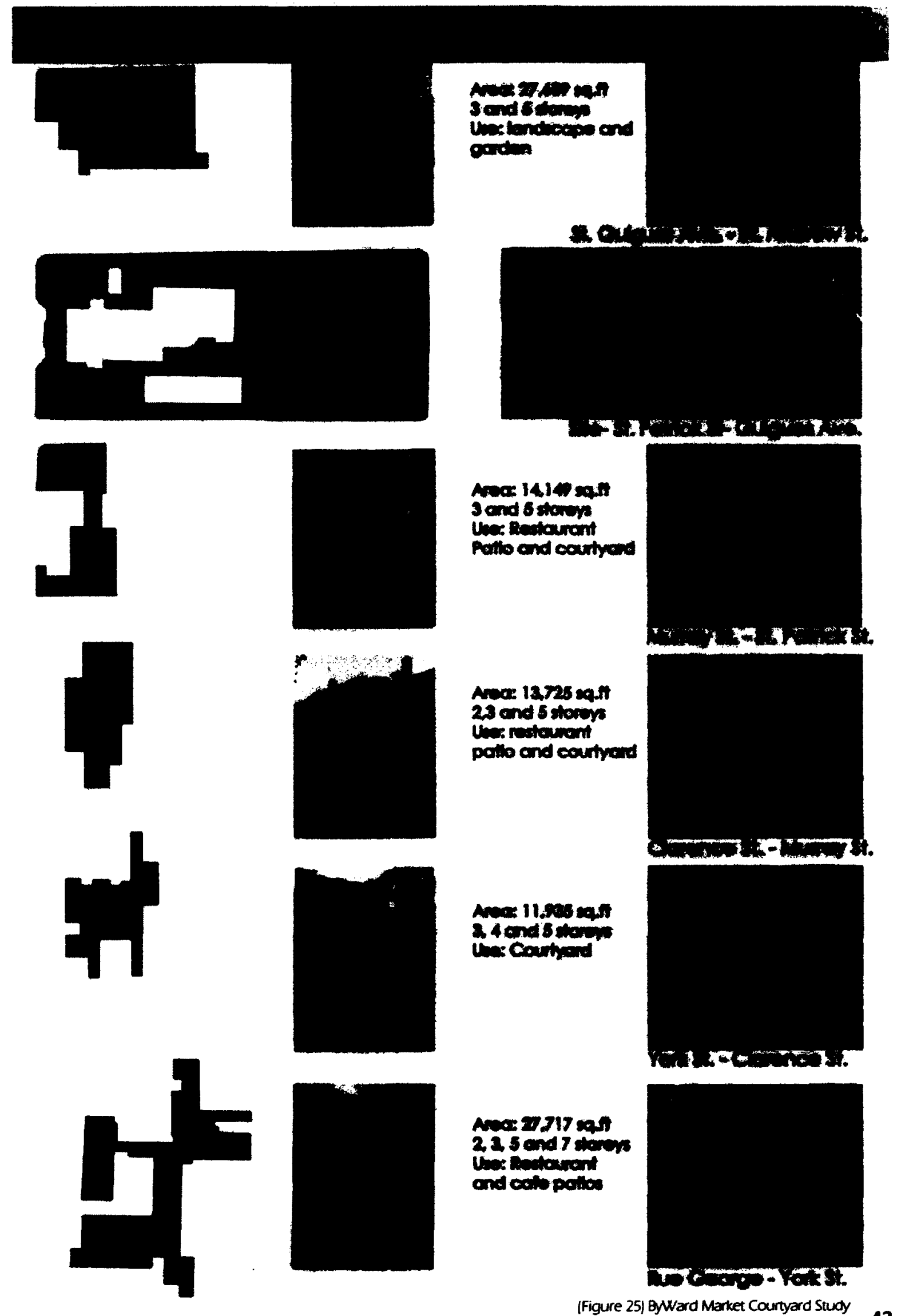



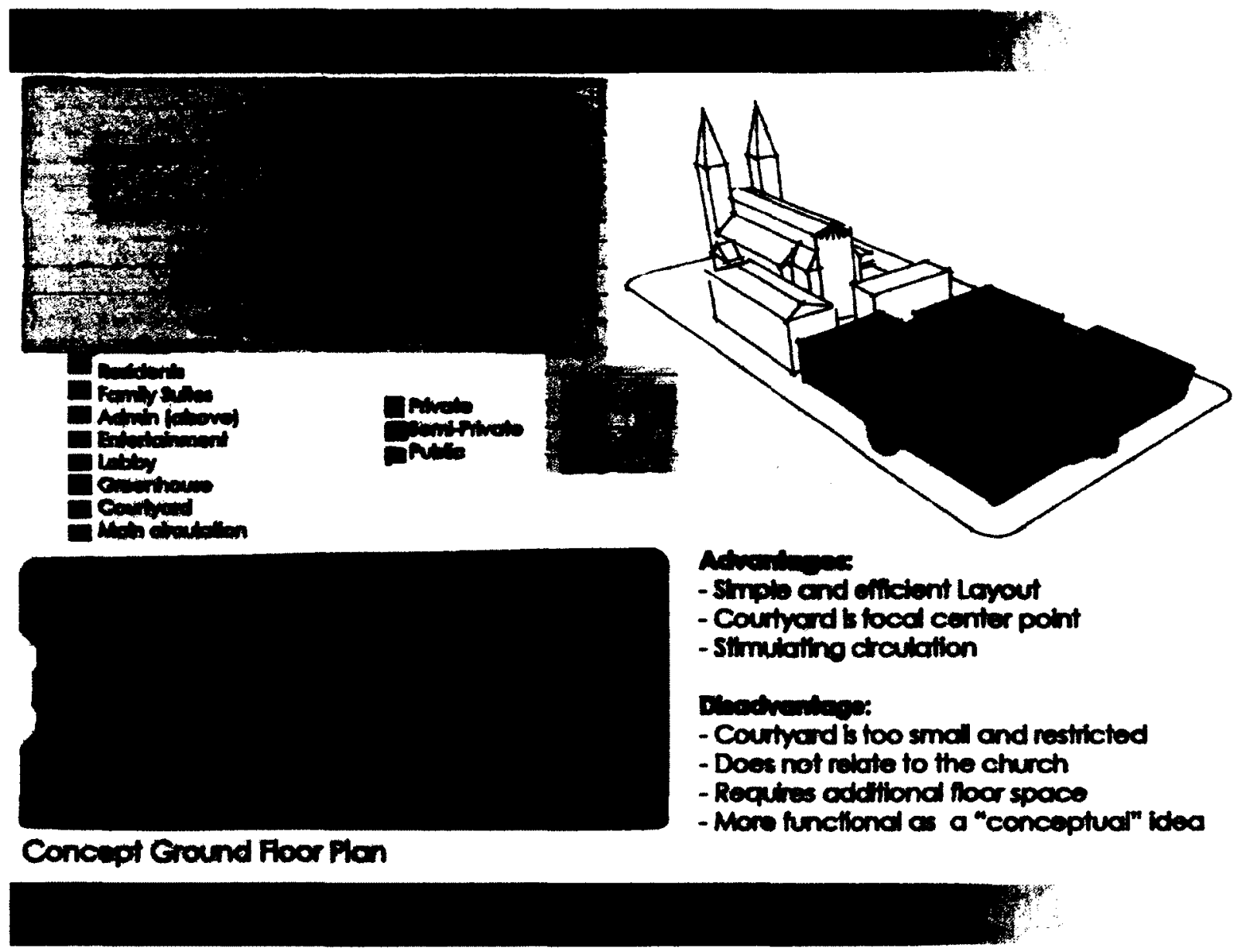

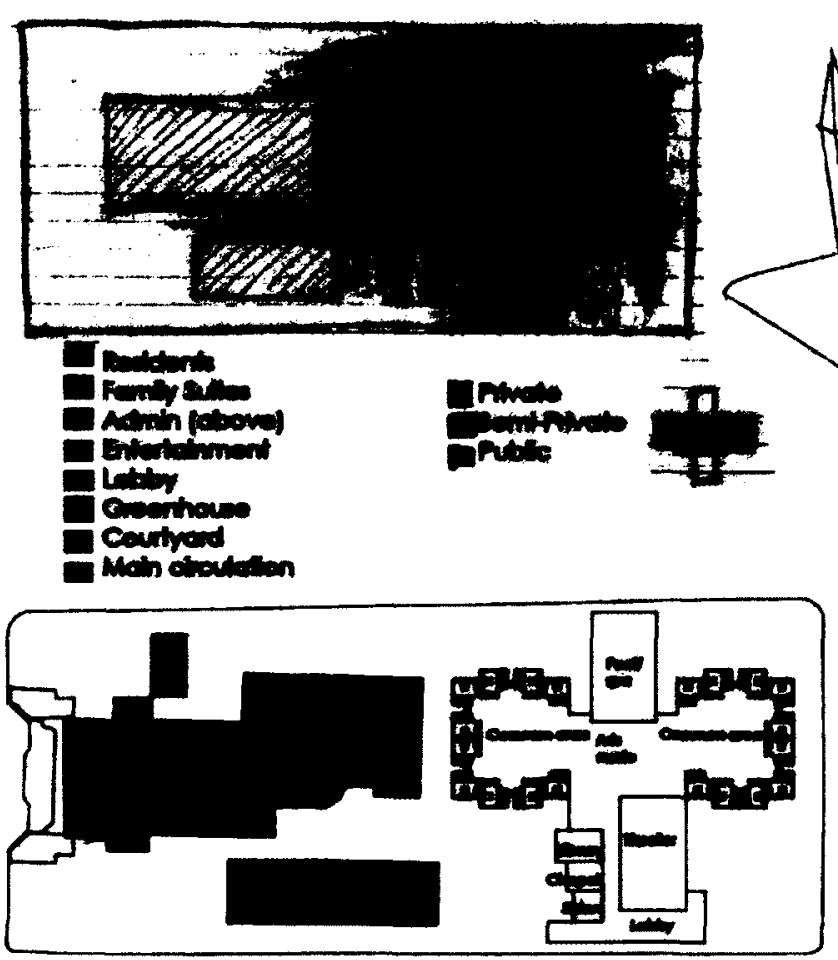

Concept Ground Foor Flon
Advontarese

- Impla and efillient Layout

- No contidos

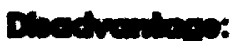

- Lares open epace man be too simulating

- No courtyod

- Addilional toor space required

- Ablirety locoted on the sito 

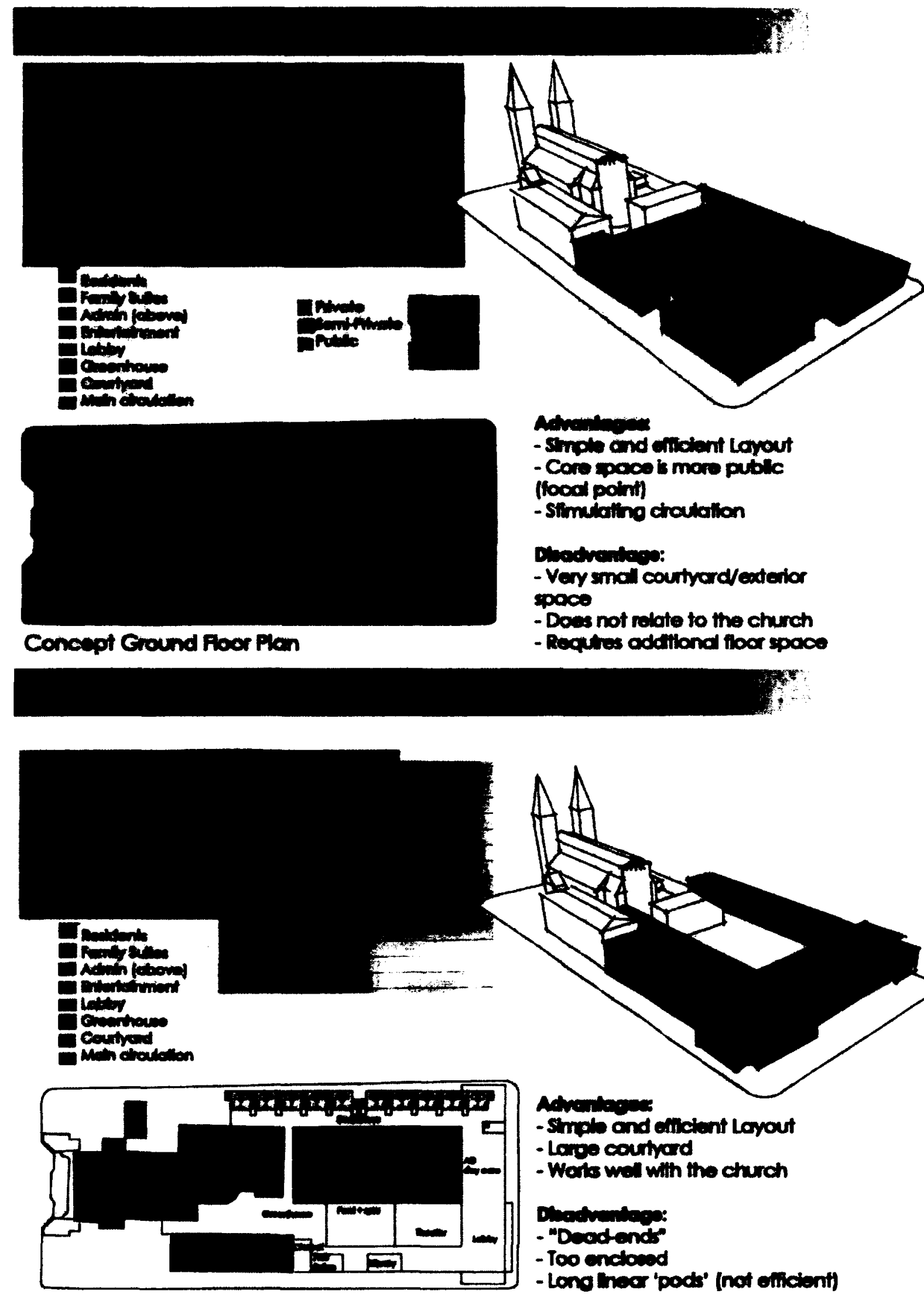

Alvernerex

- Simpis and efilcient Loyout

- Lorge coutrard

- Worts well with tho church

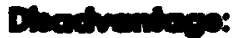

- "Docodends"

- Too enclosed

Concept Gound Focr Plon

- Long lnecr 'pods' (not efircient) 

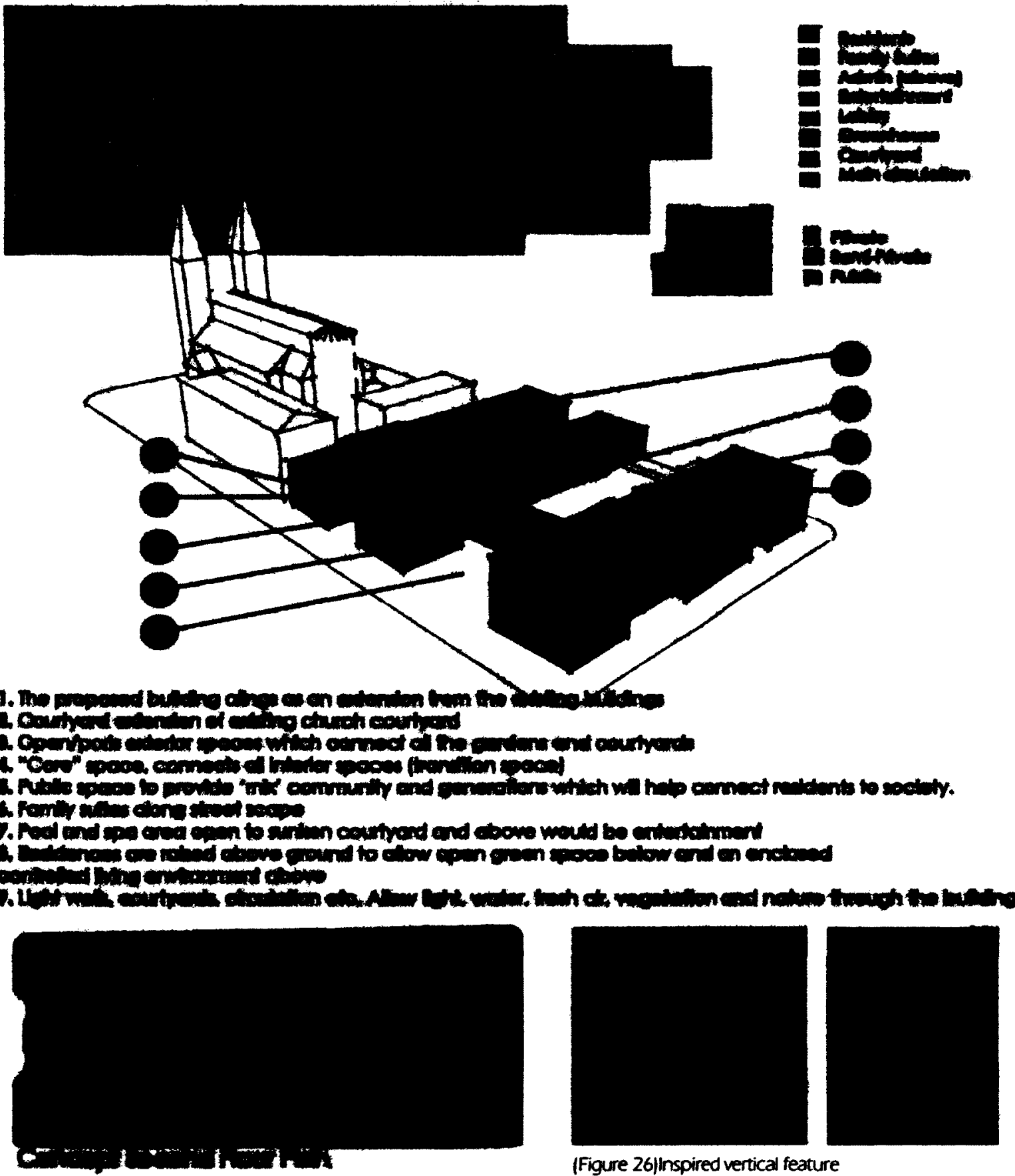

(Figure 26)|Inspired vertical feature

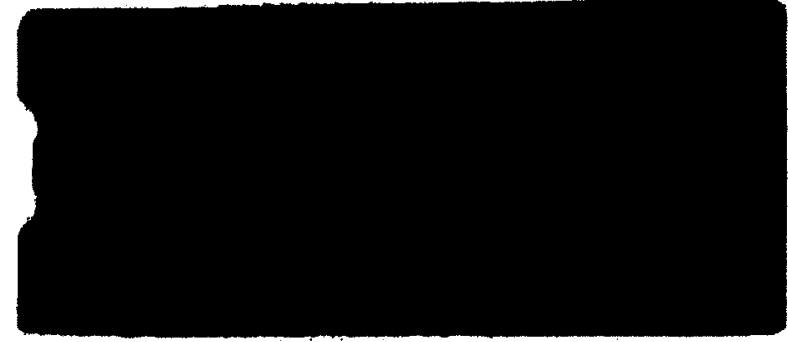

Ammenmong

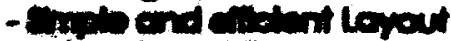

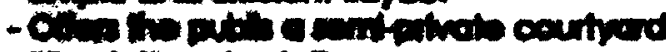

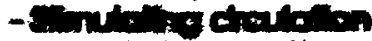

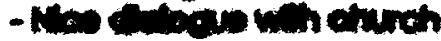

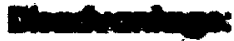

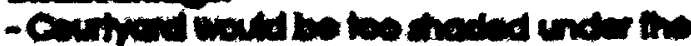

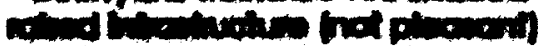

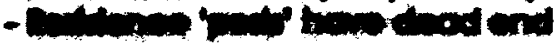




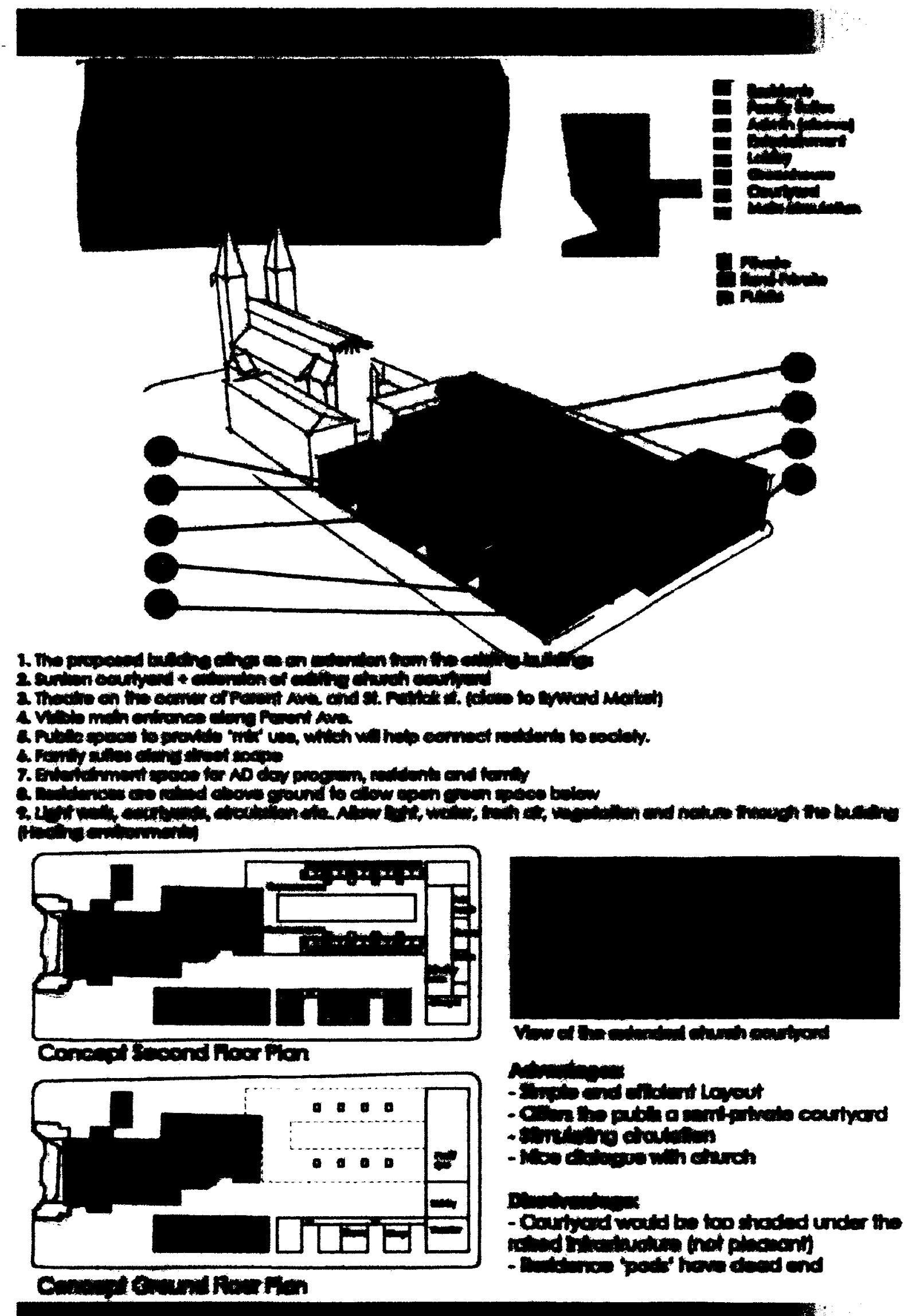




\section{Chapter 6: Proposed Design}

\section{Program}

The proposed program circulates around the idea of family time and promotes family to enjoy visits with their loved ones. The spaces will encourage communication and activity with residents and family members. Programs will allow a child and his/her grandparent to experience and enjoy the spaces together, enabling family members to take mutual pleasure in their visits. The program will also provide family suites where family members can stay for extended periods of time, supplying the family with a home-like setting. This is of particular convenience to out of town relatives and could make the difference between frequent visits and seldom, mere "token" visits. The communal spaces such as the theatre, library, green house, gardens and activity rooms will be additional programs to stimulate activities for residents with their families. The building layout is based on sun orientation, existing surrounding context, and the concept that every primary space will face the courtyard.

The goal for appropriate design strategies with regards to dementia and $A D$ is to:

- Decrease stress and depression by providing residents a sense of freedom and independence, while maintaining security and safety.

- Promote perseverance of physical, mental and social abilities.

- Provide opportunities to enhance memory.

- Create sensory stimulation /orientation, sense of control, reinforce concept of time, place and season)

- Maintain a peaceful environment, reducing fear and negative behaviour by providing comfortable environments. 
- Simple layout, wandering paths and visual cues to help navigate residents in optimal daily functioning. with many spaces allowing for increased activity and mobility with family.

- Facilitate longer and more frequent family visits with the hope of stimulating multi-generational visits.

The major components of the program are, residences for people with $A D$, an $A D$ day program, a daycare for children, family suites, entertainment amenities (includes, theater, library, spa, fitness center, arts and crafts room and music room), a choreographed circulation element, a wellness center, a greenhouse, and outdoor spaces. 


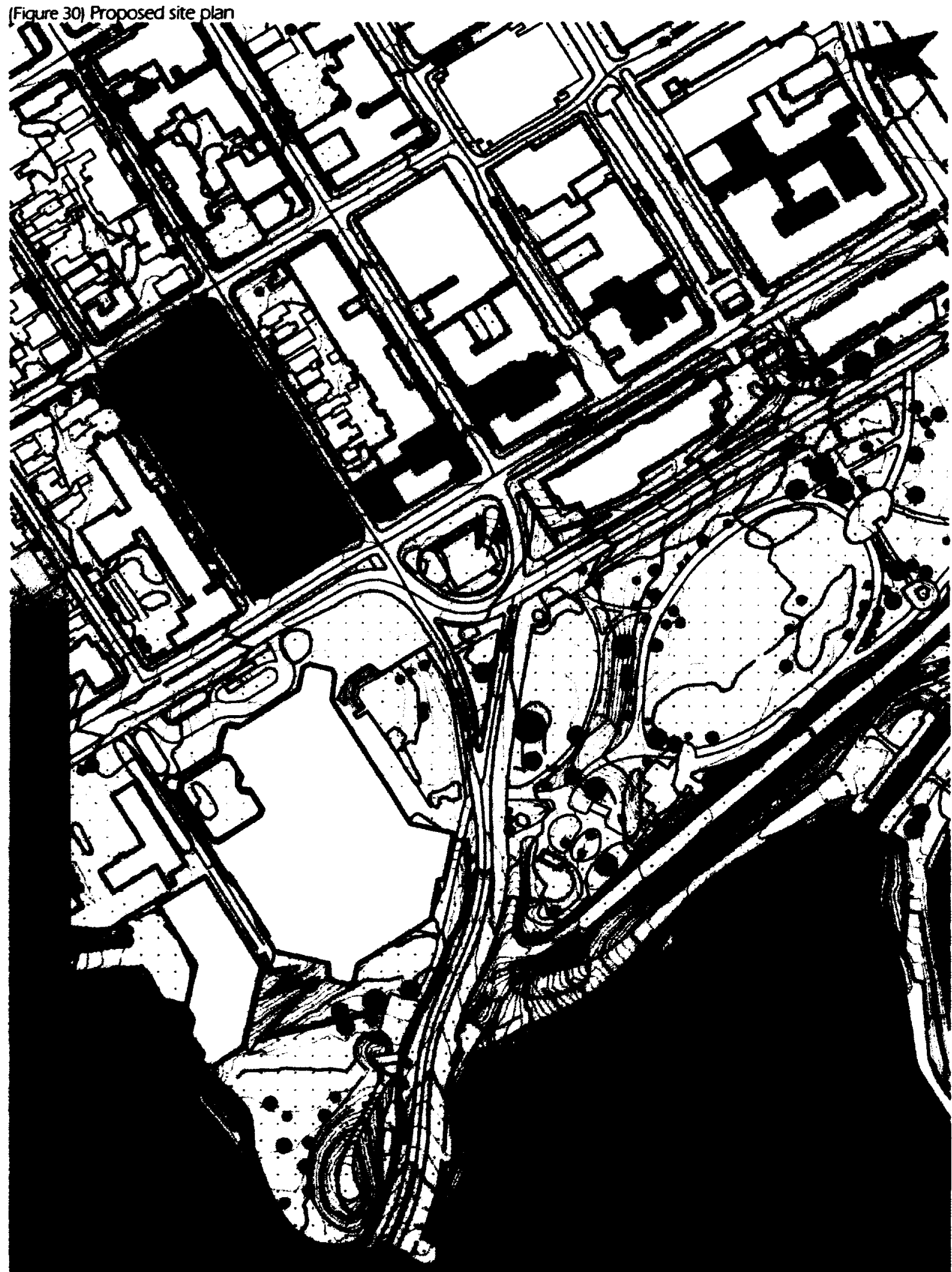




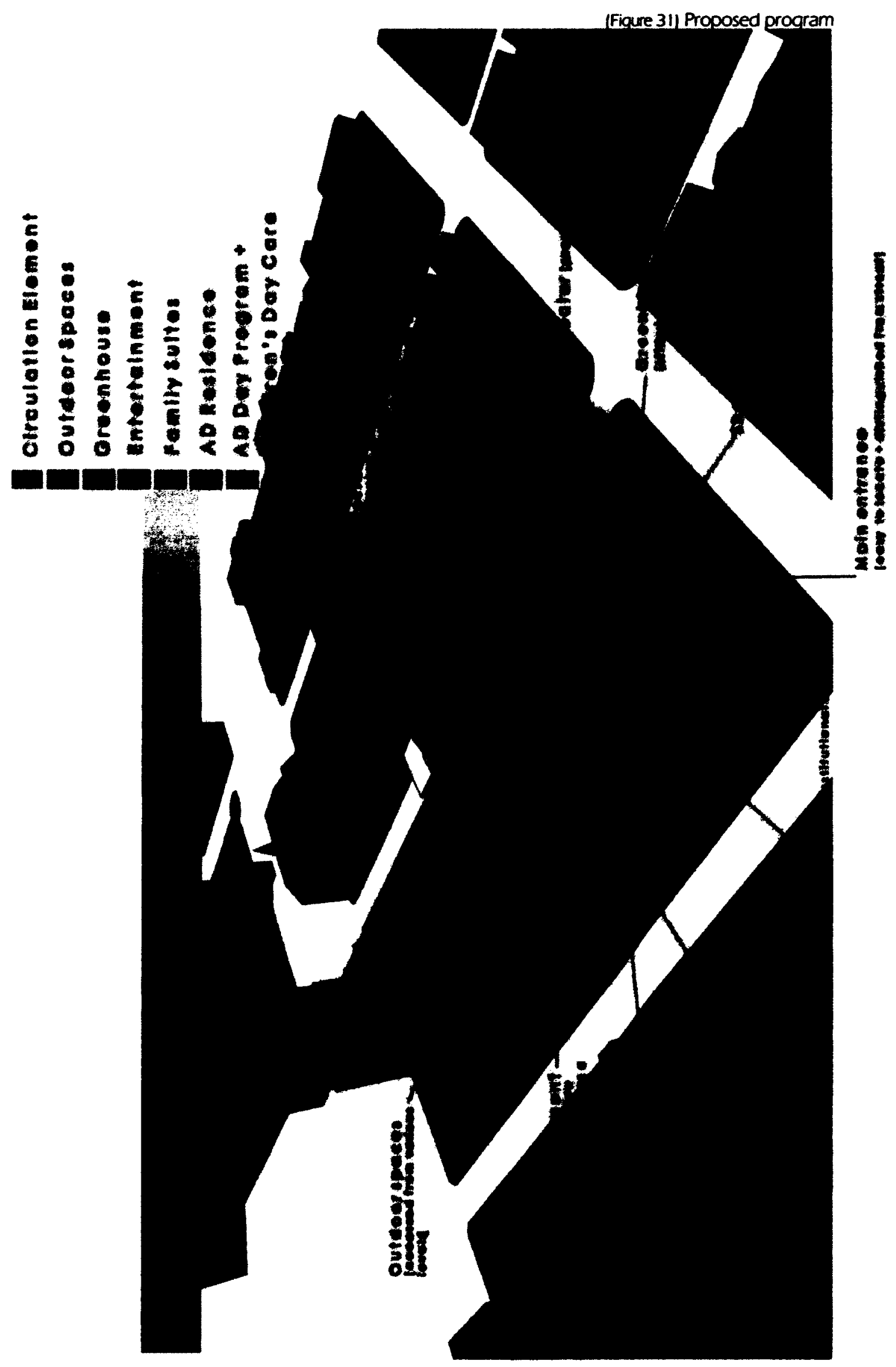




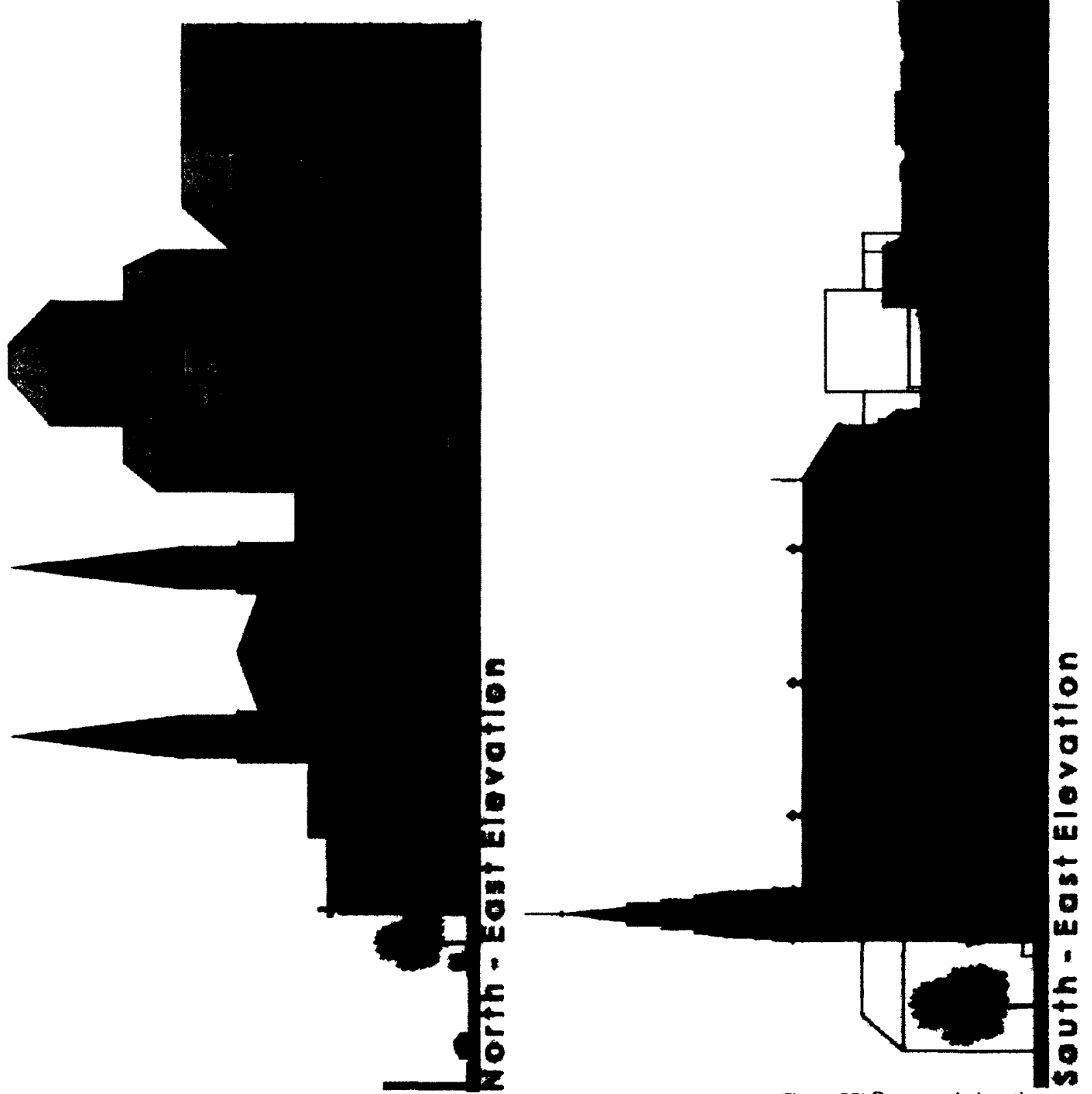

(Figure 32) Proposed elevations 


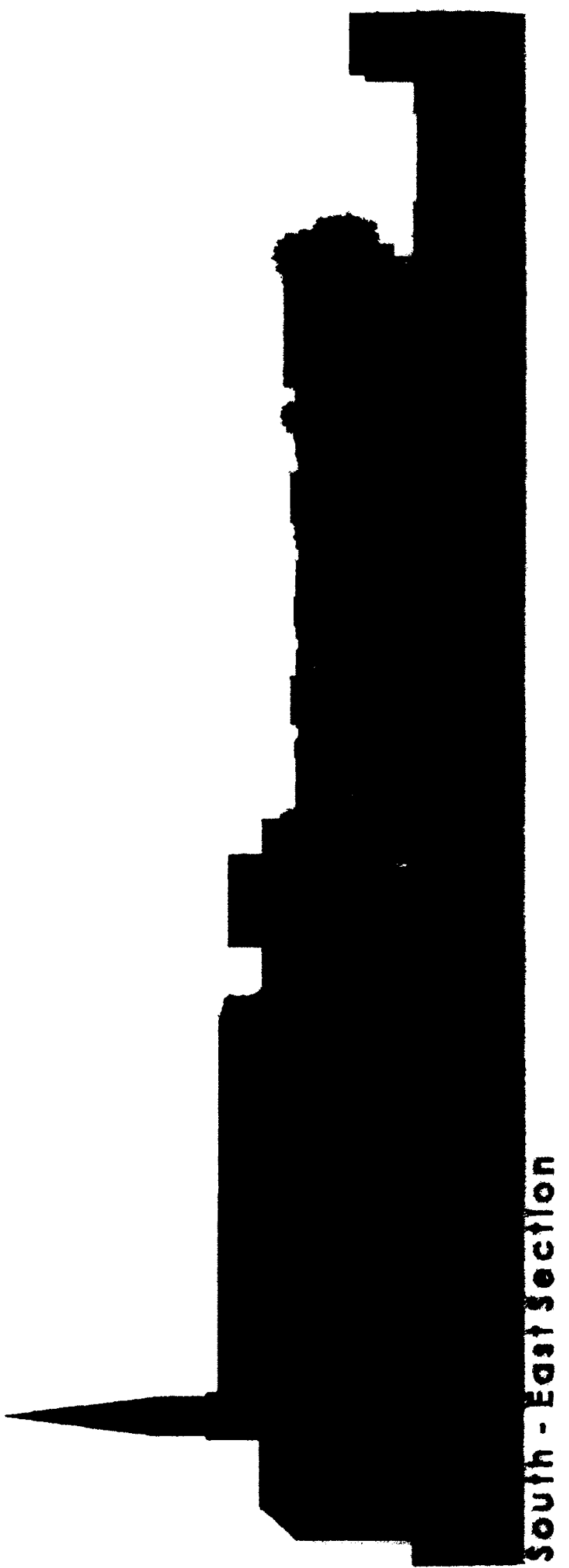

(Figure 33) Proposed section 


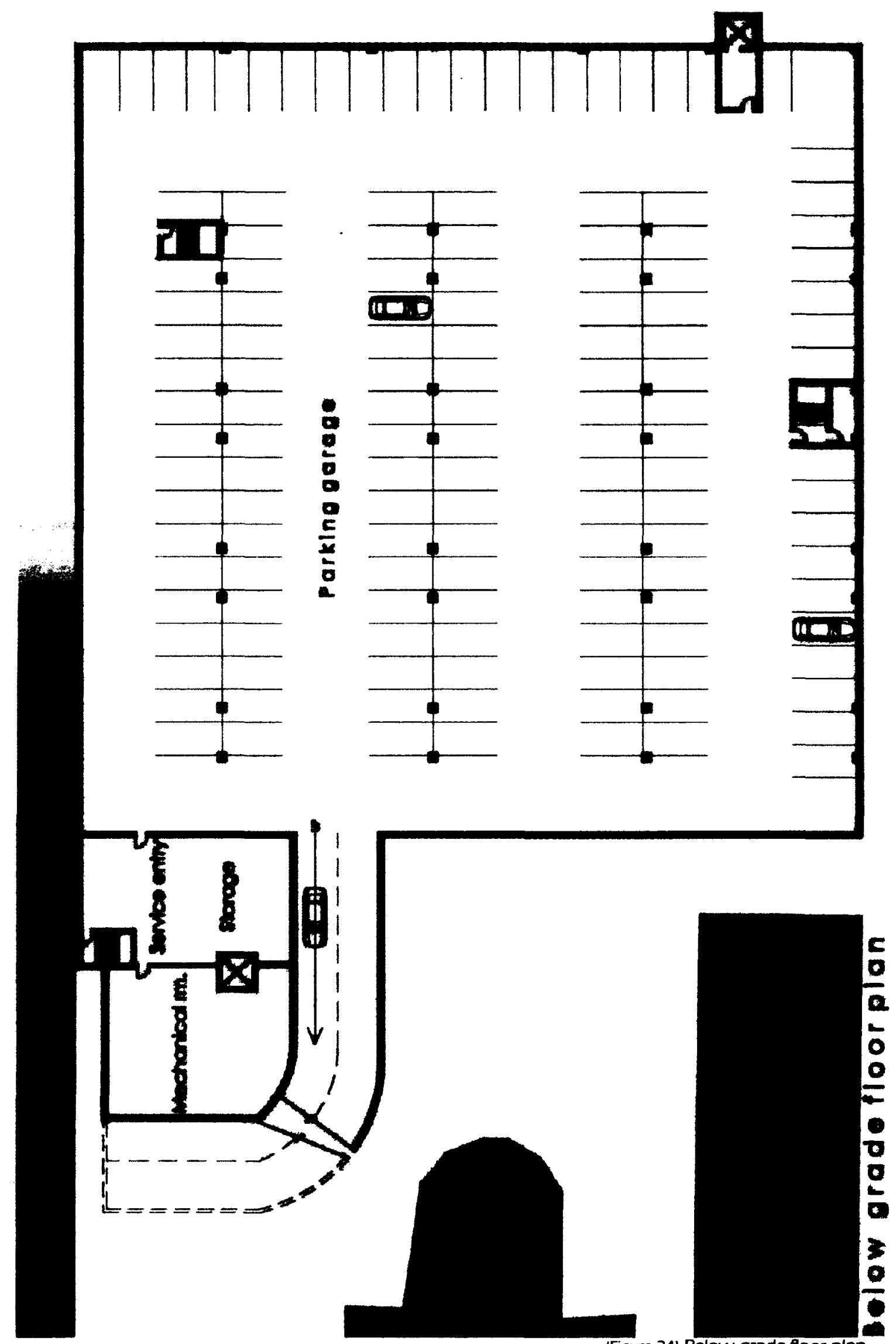




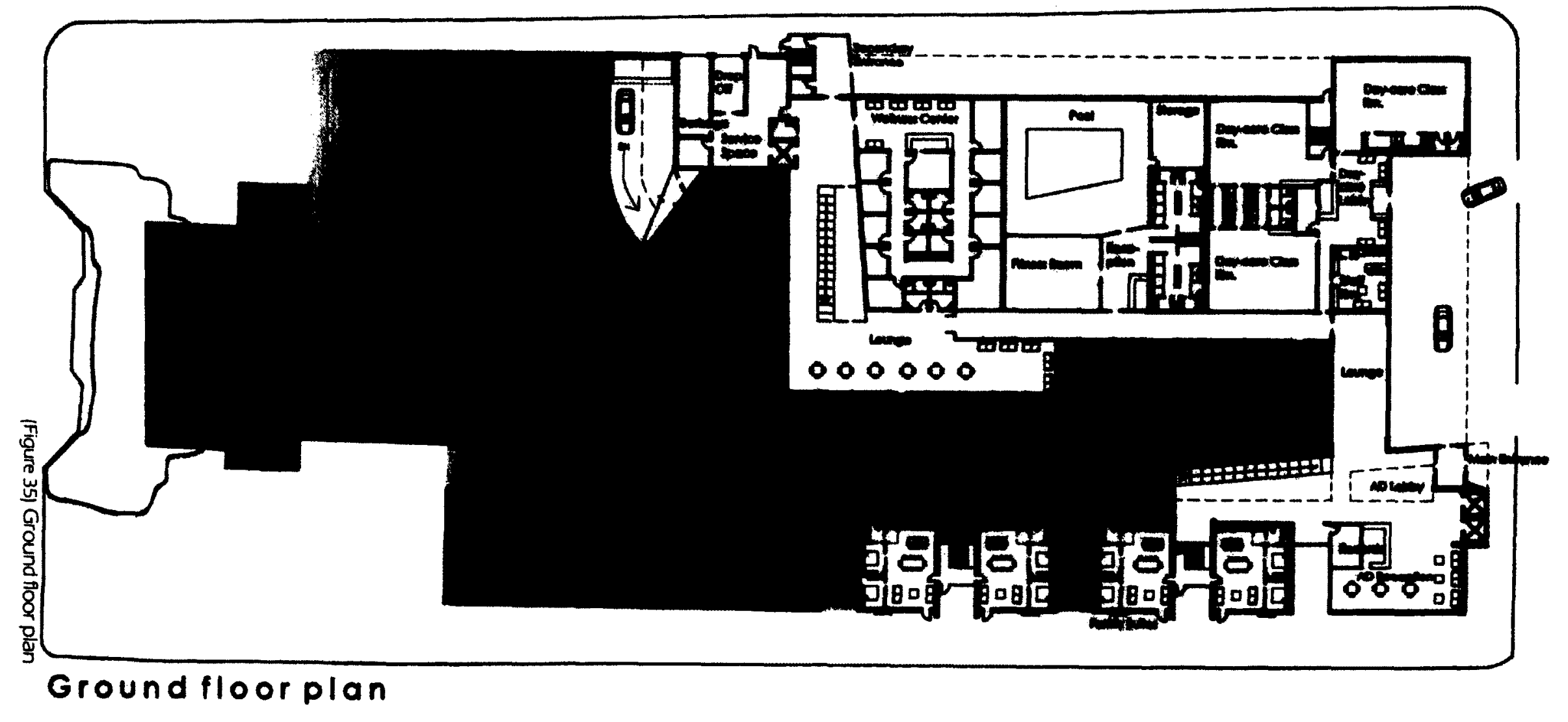




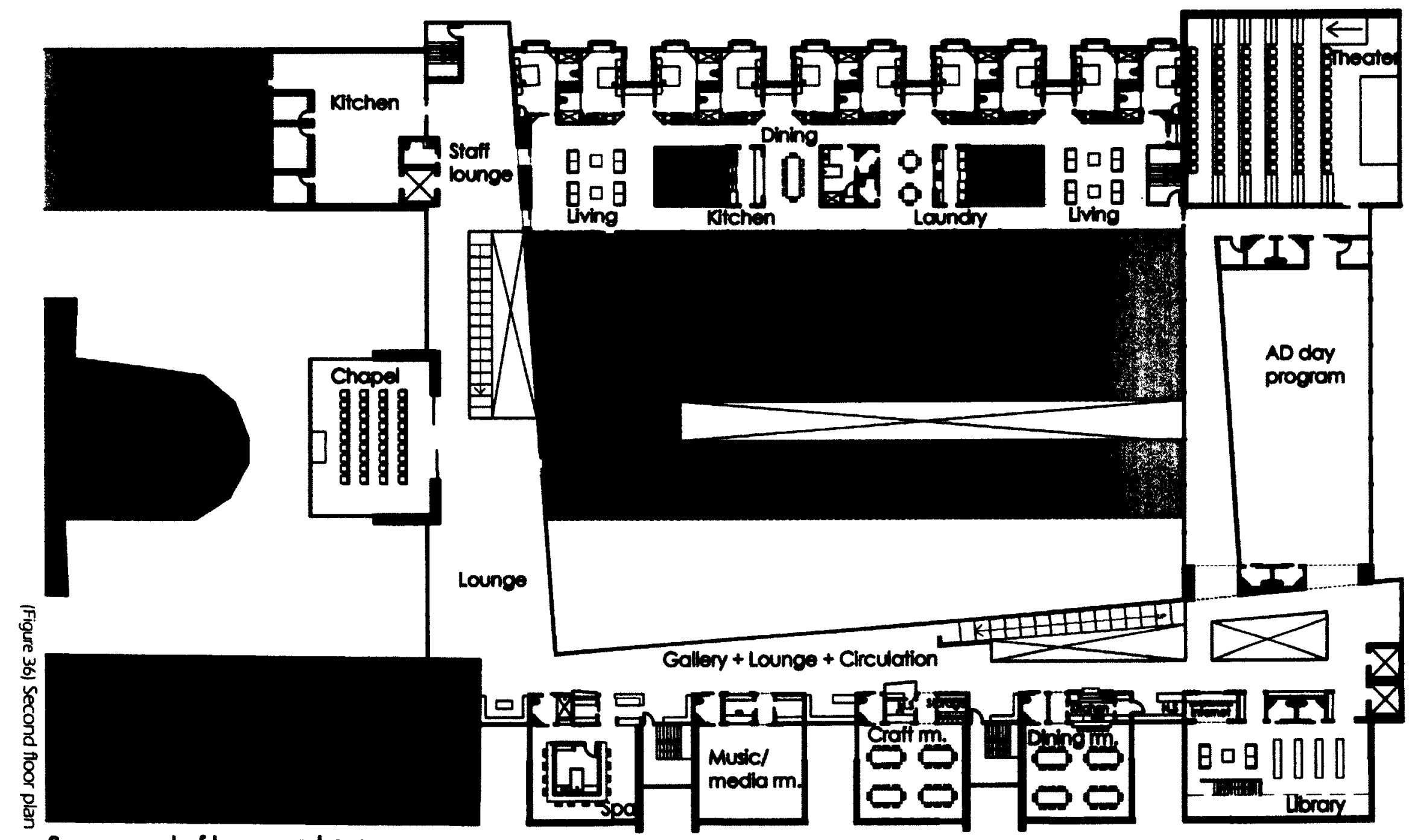

นั 


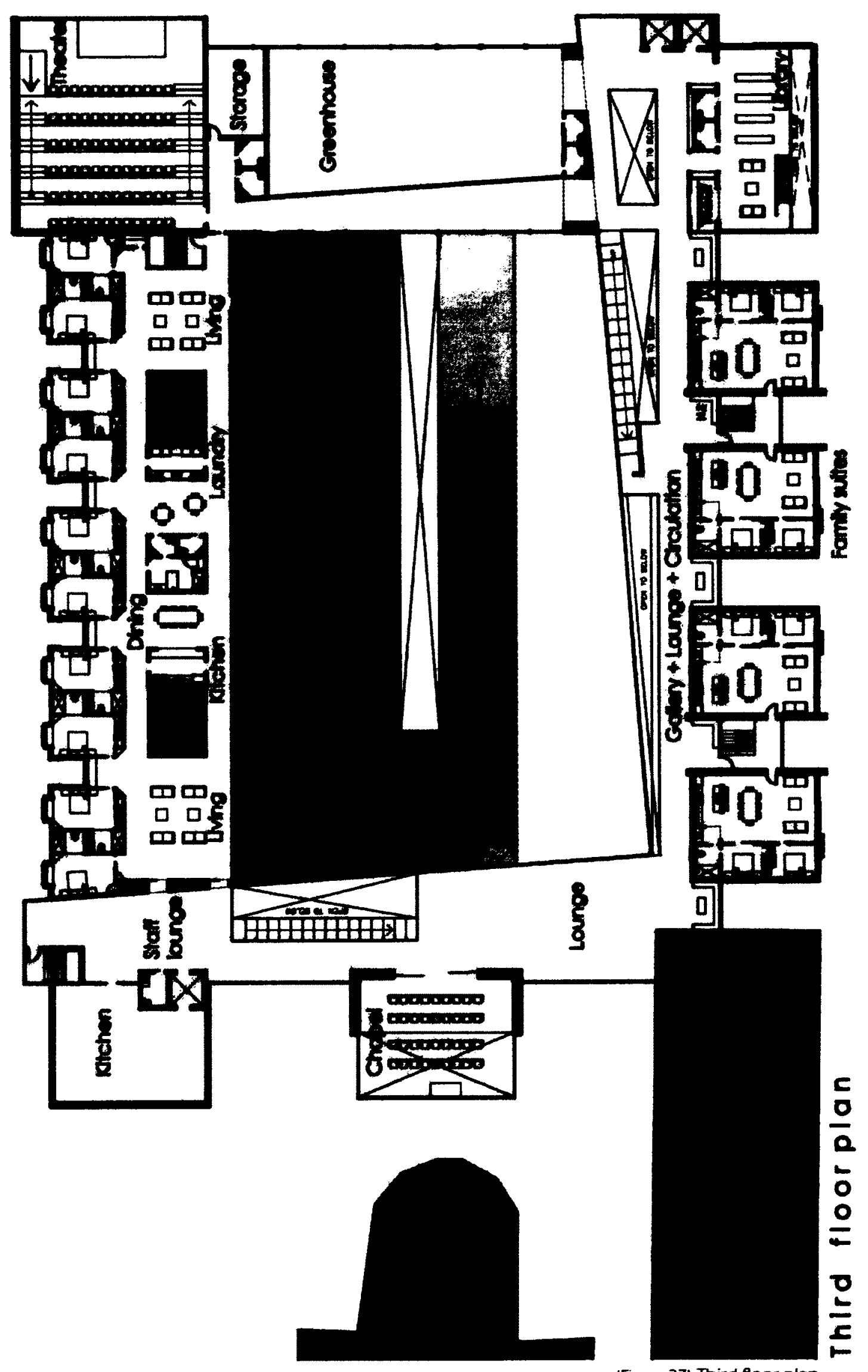

(Figure 37) Third floor plan 


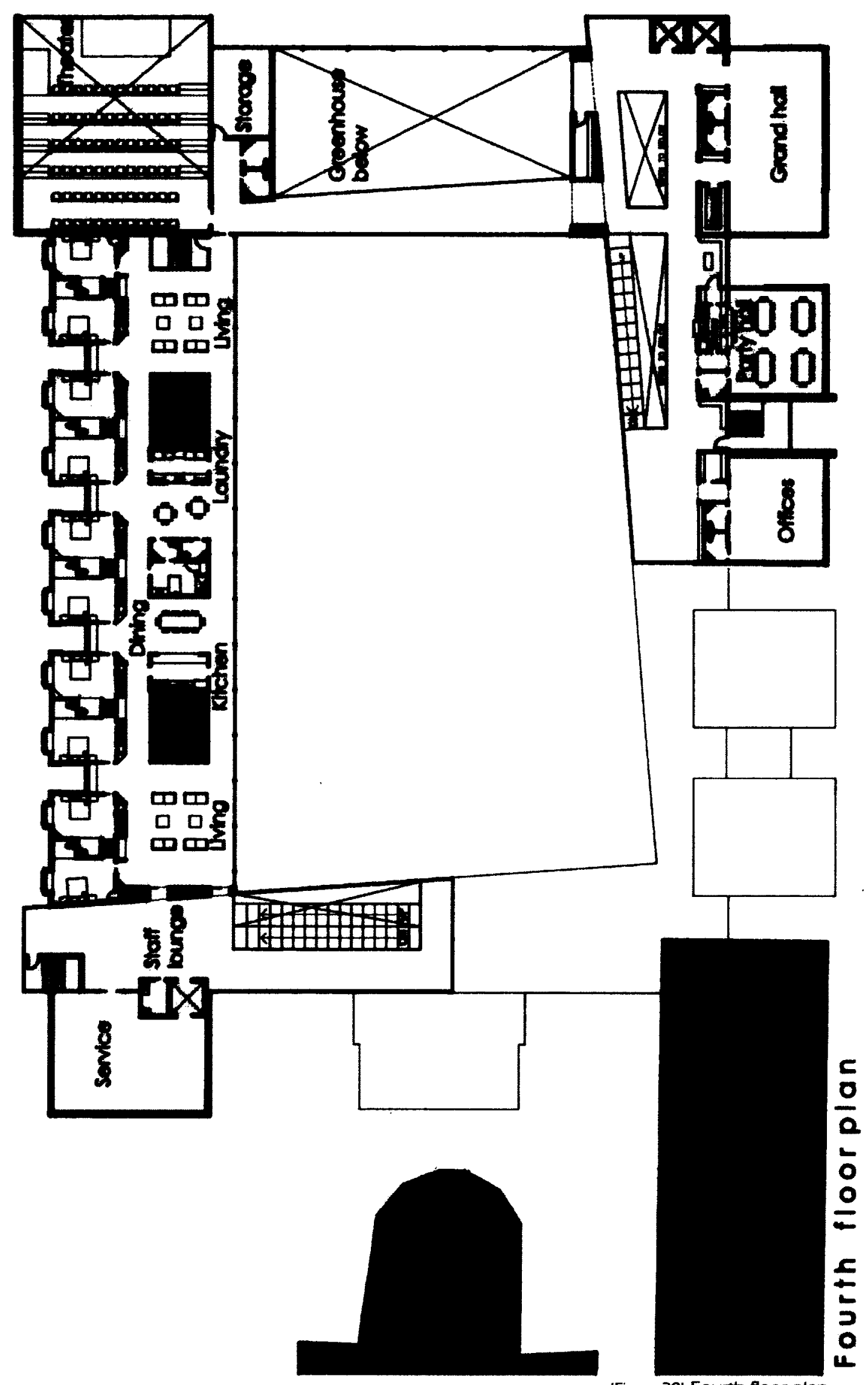




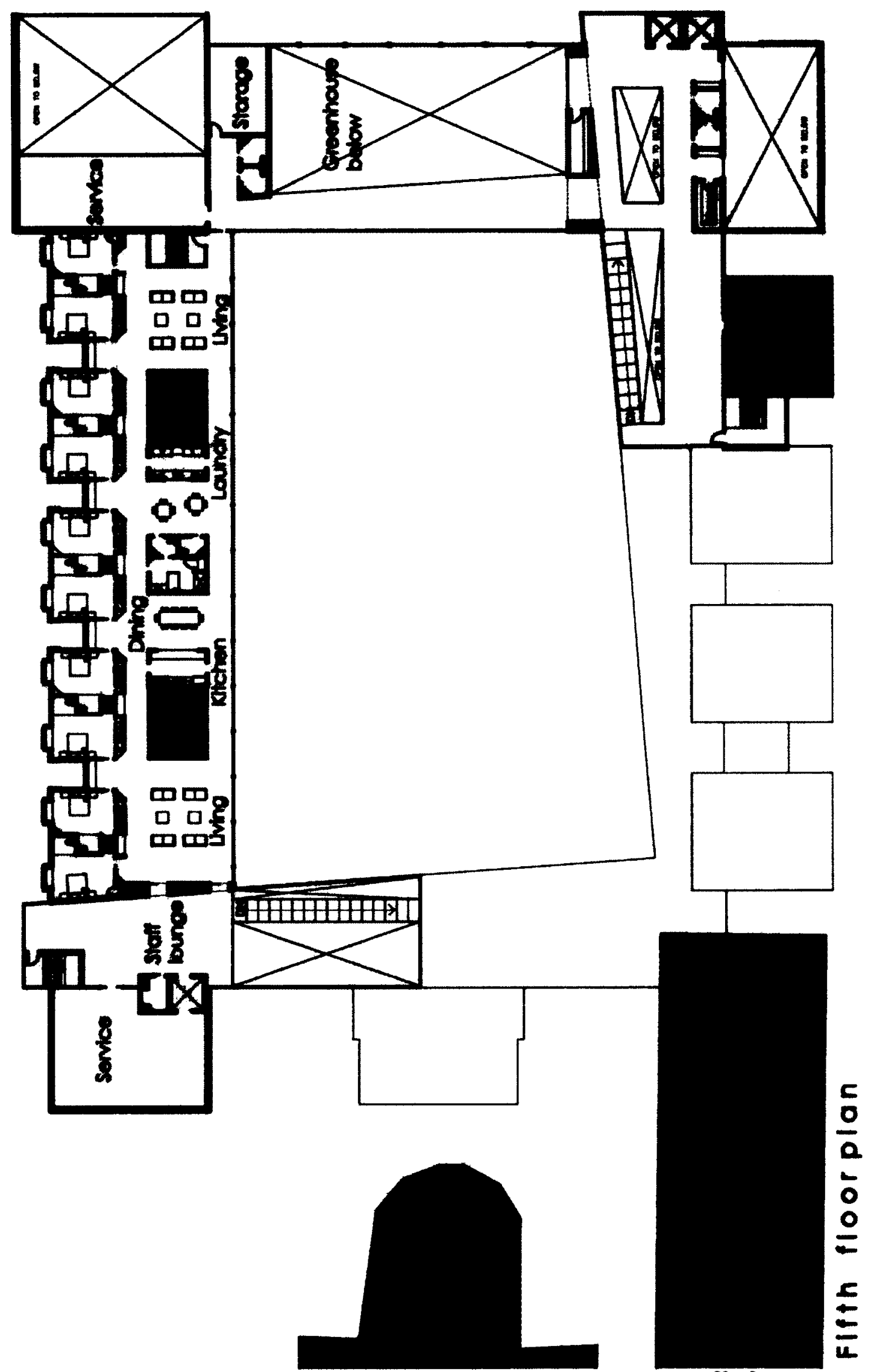

(Figure 39) fifth floor plan 


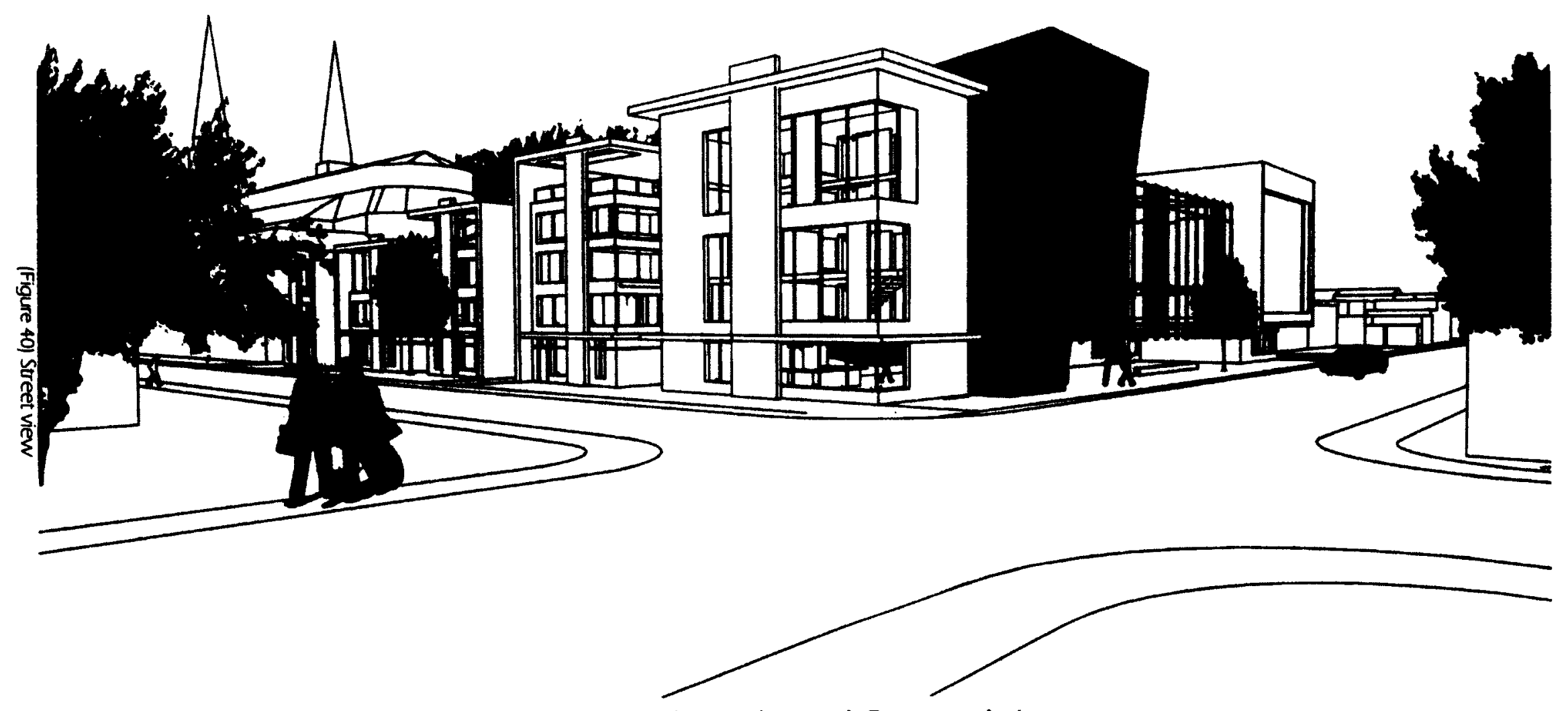

Vlew from corner of St. Patrick streetand Parent Avenue 


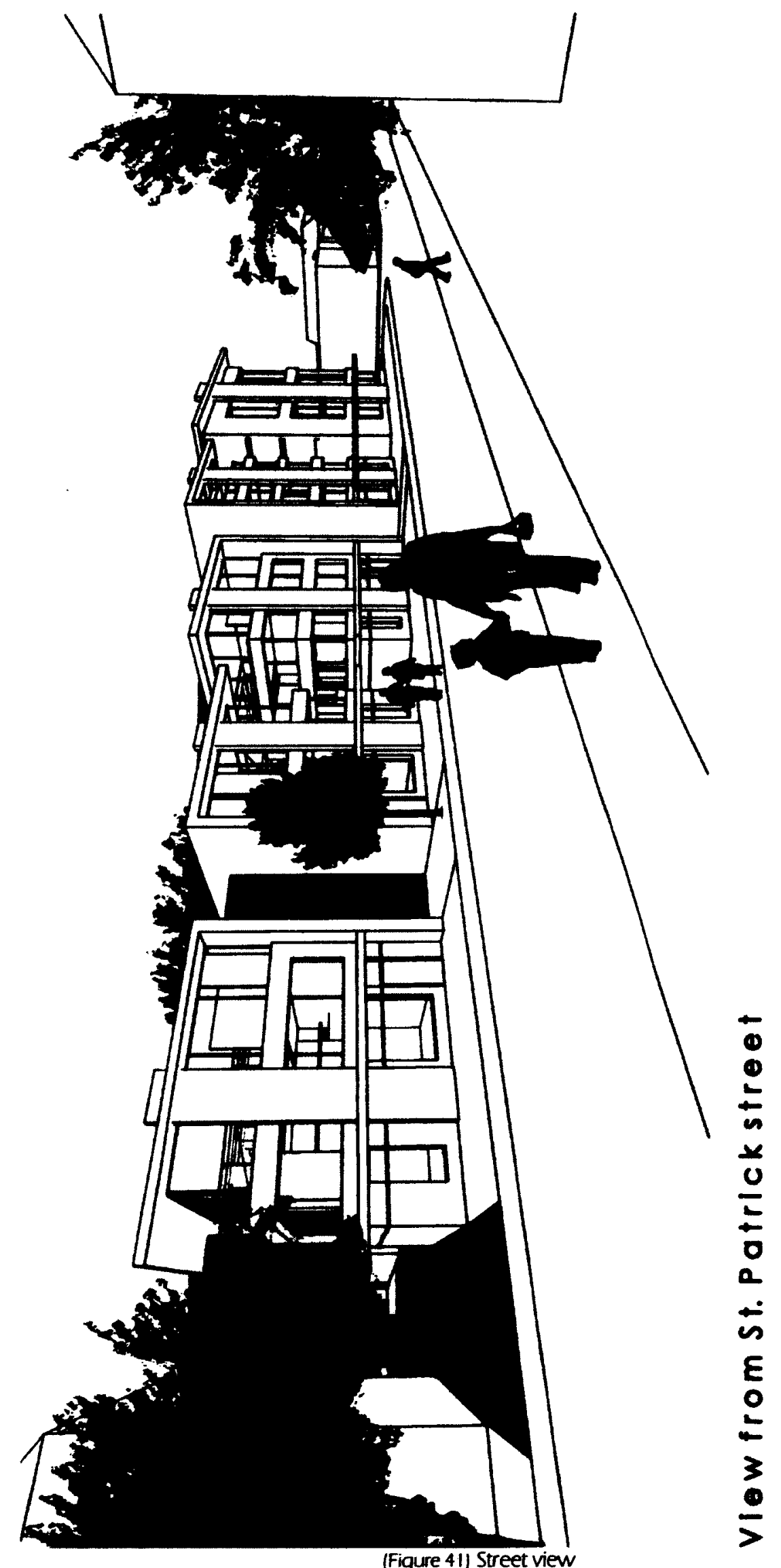

(Figure 41) Street view 

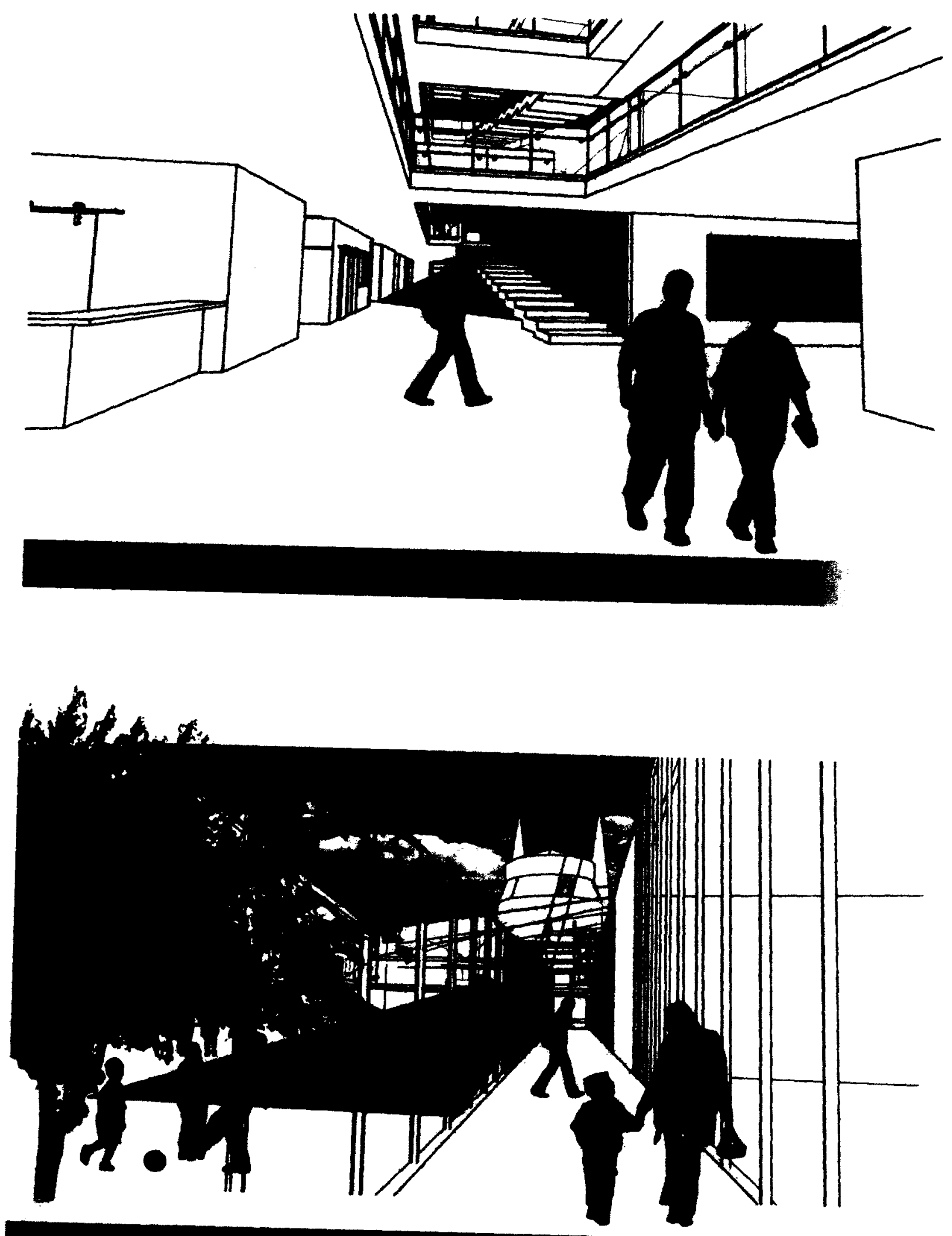

(Figure 42) Lobby view + light well and circulation view 

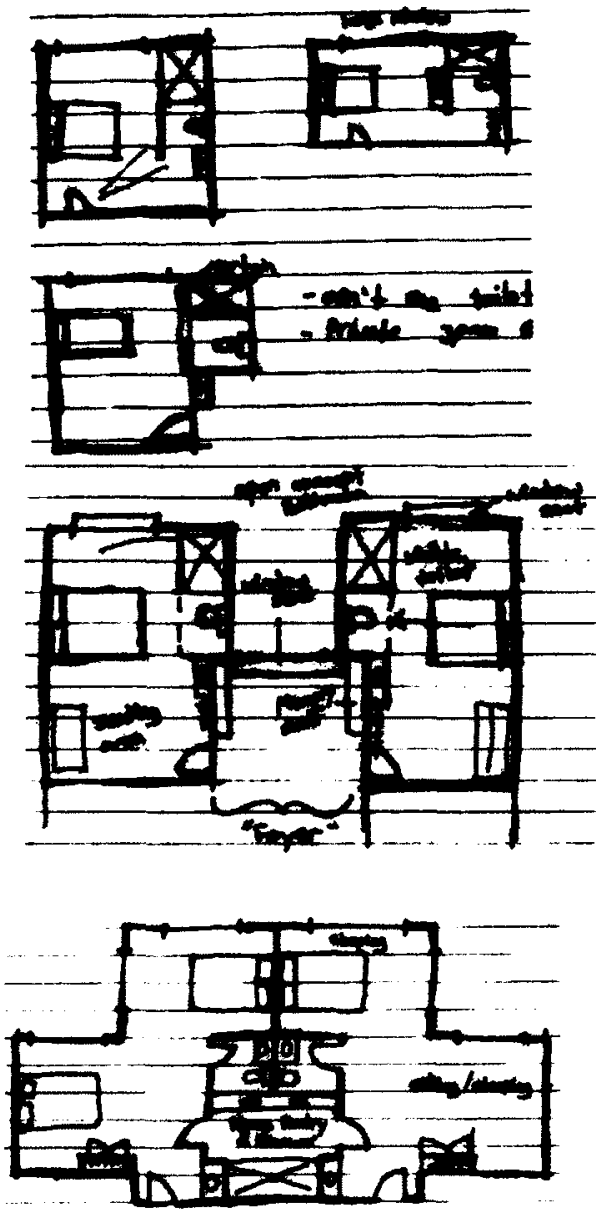

(Figure 43) Preliminary room Layout

Pod: cluster of ten bedroom's which will branch off of the main living space. This will provide a comfortable home like setting to encourage socialization and limit walking distances.

\section{Richmond Care Home Center.}

The Richmond Care Home is a 16-bed Alzheimer's home dedicated to the care of women with dementia. It is designed to enhance independence by allowing the residents to partake in each daily task through a caring, comfortable and safe environment

[hup//unwwcarefor ca/richmond-care-home/]

\subsection{Residences}

The residence pods will be located on the north/east side of the site and will be on the second to fifth floor. This location was chosen since it is furthest away from the Ottawa Byward Market and its heavier traffic. To eliminate corridors, the residences branch off of the main living and dining areas. This shared space is located along a large glass area that would overlook the courtyard and maximize sunlight entering the building. To maximize light on the parallel side, each second bedroom (figure45) will be separated with a bench and large window allowing for cross ventilation. This area will further create a personal 'foyer' to each bedroom which will include a place to sit, and a memory box to help trigger residents past memories and to help them locate their room. The concept of 'pods' is similar to the Richmond Care home Center in Ottawa, which functions around the idea that residents will participate in daily task such as cooking and doing laundry. As mentioned in chapter three, participating in familiar everyday chores enables residents to feel more independent while creating a comfortable memorable environment. Initially, there was consideration given to the notion that each 'pod' would have a different theme, color or material to help identify each 'home' and help stimulate memories However, in the book Building Type Basics for Seniors, researchers have stated that subtle cues such as changes of color or material have not been successful, and that major landmarks, such as, for example, a grandfather clock or features that engage other senses 


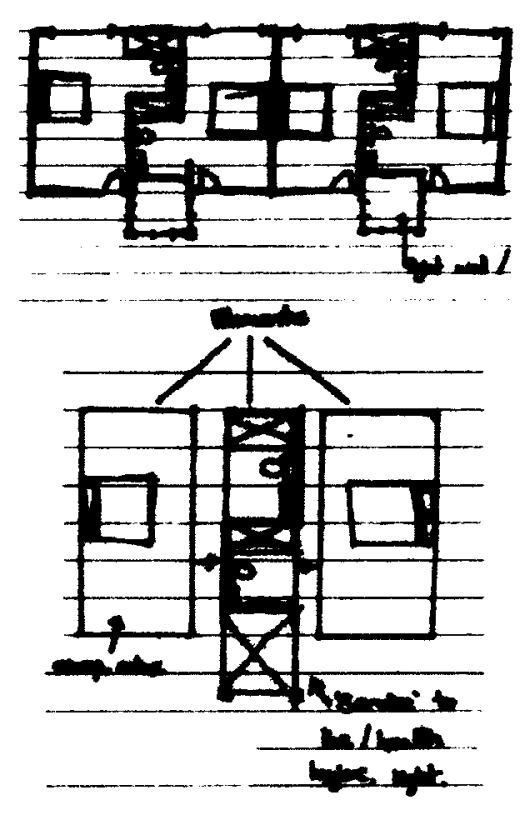

(Figure 44) Room layout sketches

are more effective. ${ }^{54}$ Therefore, large vertical elements (Figure47) were included in the design as major landmarks. These vertical elements would run through each 'pod' floor and create various light wells and small personal courtyards. These spaces would engage senses such as sight, smell, touch, and sound, by allowing nature to be in close proximity. Next to these 'landmarks' residents will be able to hear the birds chirping, the sound of falling rain water and feel the sunlight on their skin. (This will create nurturing physical spaces for residents to observe, experience and enjoy.

${ }^{54}$ Bradford Perkins, David Hoglund, Douglas King, and Eric Cohen, Building type basics for senior /iving. (New Jersey. Wiley \& Sons, Inc., 2004), 236. 

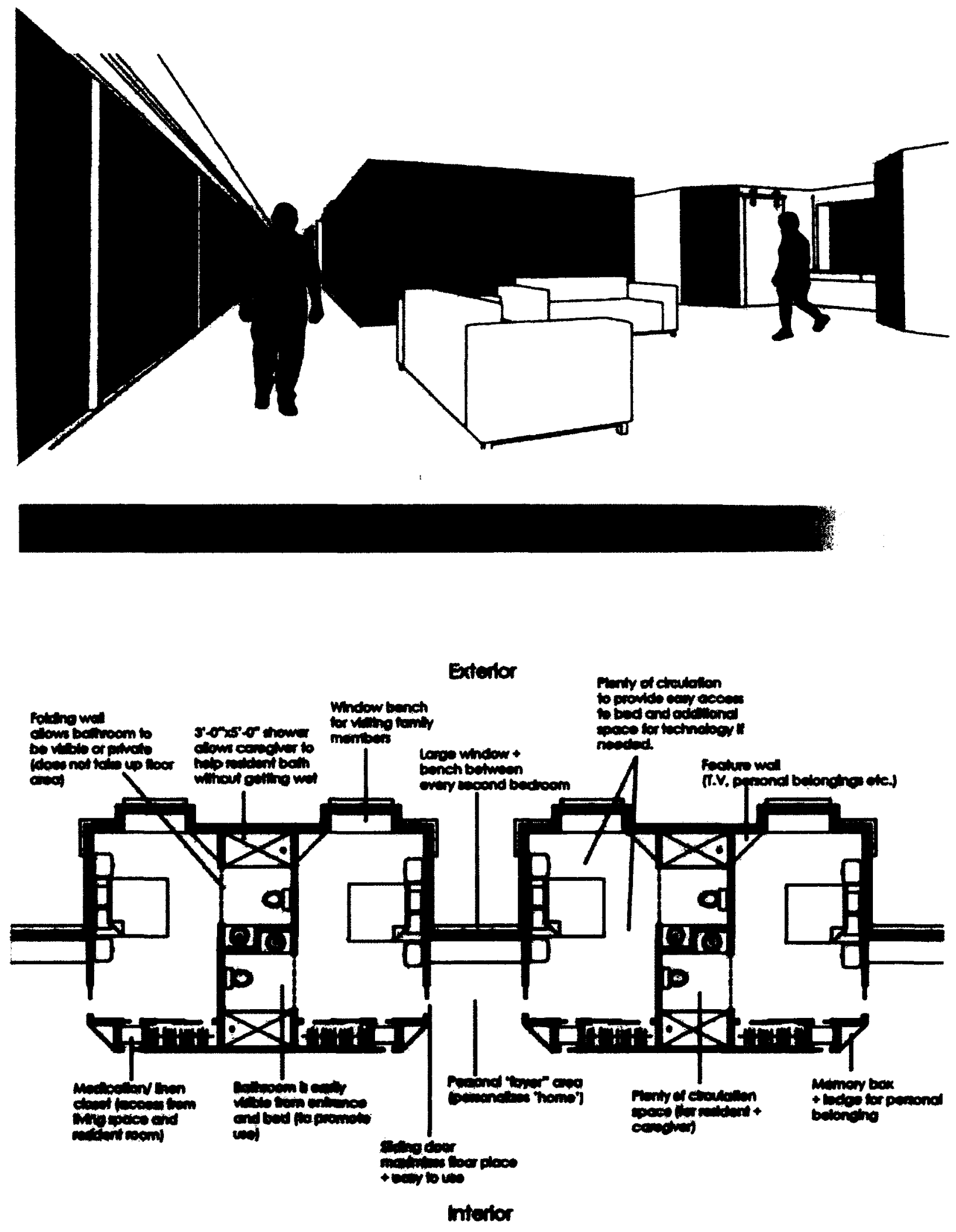

(Figure45) Proposed room layout and 'Pod' view 
(Figure 46) Residence 'pod' axo
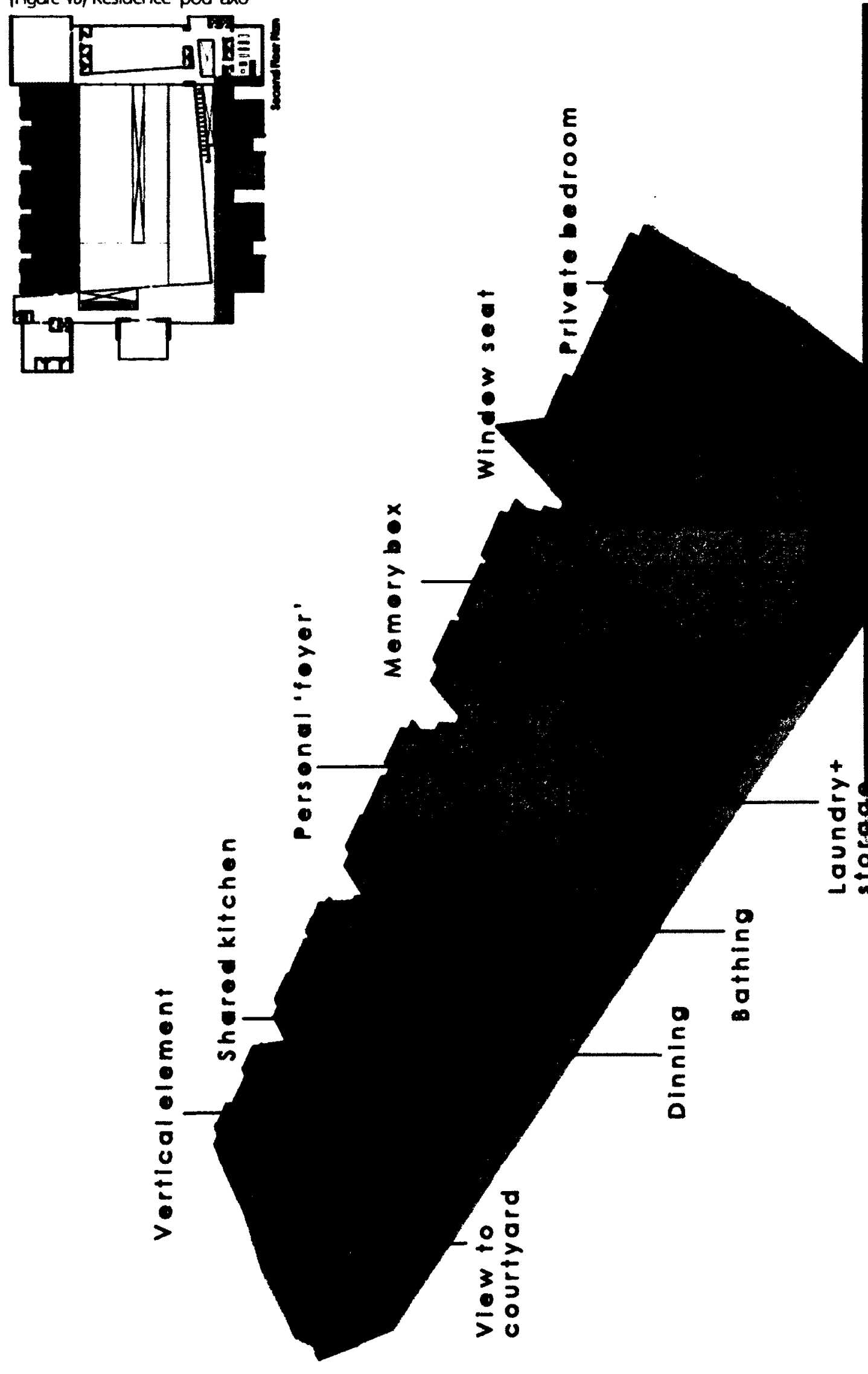

$+$

2 58 5 원 


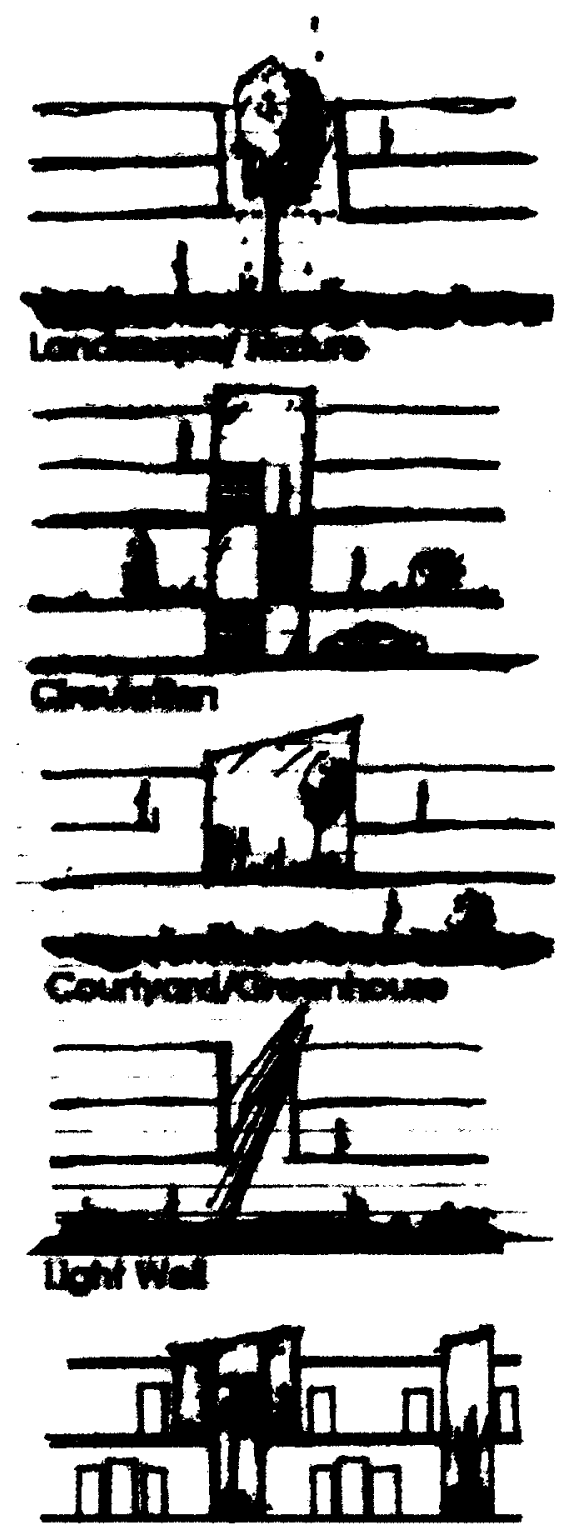

(Figure 47) Proposed vertical elements

\subsection{AD Daycare Program}

The AD day program provides a therapeutic environment for people with AD. It allows the person with Alzheimer's family to go to work, or relax for the day, knowing their loved one is in good care. The program focuses on stimulating all senses, through various environments and activities. The $A D$ day program reception and administration will be on the ground floor; however, the AD day program itself will be located on the second floor and will share entertainment amenities with the permanent $A D$ residents. Having the $A D$ daycare program and Alzheimer's residents located on the second floor will allow residents and daycare individuals to liberally explore the 'entertainment' floor, avoiding any chance of them exiting the main entrance located on the floor below. In contrast to other healthcare centers where the front entrance is exhaustively used, this facility will function on the understating that people with dementia or $A D$ rarely leave the facility, thereby allowing the entrance to be primarily dedicated to visitors and employees. 


\subsection{Family Suites}

The family suites are designed based on the idea that the residents would greatly benefit from the greatest degree of family interaction possible. The suites are, therefore, created as a place for family members to stay for an extended period of time. There will be eight suites, which will be located on the ground and third floor along St. Patrick Street, across from existing single family homes. These dwellings will have street access and will also be linked to the main building. These dwelling units are 980 sq.ft each and have windows on at least two wall surfaces; the layout is simple and efficient. The family suites would promote residents and family members to be active and mobile together, allowing many generations to enjoy, socialize and participate in the provided spaces together. The proposed urban location will further benefit the entire family because of its close proximity to the National Art Gallery, entertainment, dining, shopping and other numerous nearby stimuli.

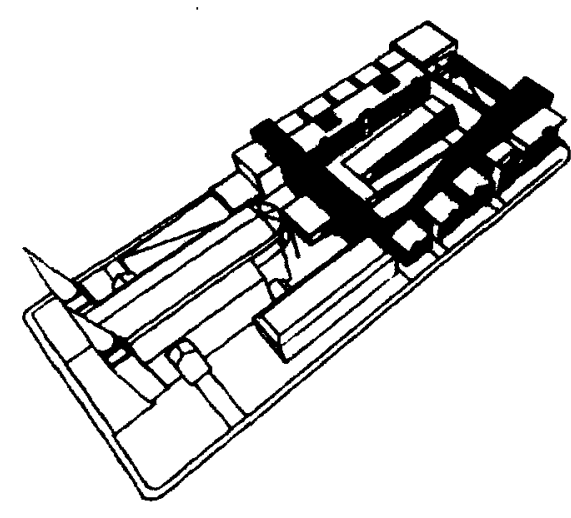

(Figure 48) Proposed circulation element

\subsection{Circulation Element}

It is common for people with dementia and $A D$ to aimlessly wander without rationale. Many designers believe the solution to this is 'wandering' loops or figure-eight pathways to eliminate dead ends; however, these design strategies can lead to catatonic like behavior or repetitive cycling without reason. ${ }^{55}$ As mentioned in chapter two, John Zeisel, believes it is important for someone with $A D$ to easily distinguish the space they are in and how they arrived. The

\footnotetext{
55 Bradford Perkins, David Hoglund, Douglas King and Eric Cohen, Bullding type basics for senior /iving (New Jersey. Wiley \& Sons. Inc., 2004), 68.
} 
proposed circulation element (figure 30 ) is, therefore, designed to encourage and help residents to easily locate and distinguish activities they can partake in. For this reason, rather than designing a 'wandering loop' with various doors that lead to an activity room on the other side, the proposed design provides a large circulation path that alters in size and shape to weave through each amenity space. This circulation feature allows residents to easily distinguish destinations and encourage them to join social events. To avoid the typical dark institutional corridor, the circulation path will have a continuous glass wall that will continually overlook the courtyard which will act as a reference point, allowing the residents to distinguish where they are and where they are going. Furthermore, the circulation route will provide various seating arrangements for rest, social gatherings, and will also act as a gallery to display artwork created by residents but also local artists. As described by Esther Sternberg in Healing Spaces, people with $A D$ and dementia maintain sensory hardwired recollections, these include, smells, sounds, materials and artwork. Using these incentives and artworks as mapping strategies to distinguish spaces can be very effective. ${ }^{56}$ Therefore, the gallery space intertwined into the circulation element will provide an additional landmark. All of the circulation in the proposed design (including vertical circulation) is well distinguished and simple to understand. Elevators can be a perplexing and aggravating ordeal for people with $A D$, as it is frustrating to leave one space and appear in a 
complete different space with no recollection of how one arrived. To help with this confusion the proposed elevators are surrounded by a glass wall in an open atrium. This aims to allow residents to feel more restful by allowing them to see and understand where they are going and how they are getting there.

\subsection{Entertainment}

Many existing retirement homes and $A D$ care facilities such as the Waterford Retirement Residence (Figure 311 in Kingston, Ontario, and the Waveny Care Center (figure 32) in New Canaan, Connecticut, design their entertainment programs to look like a nostalgic "main street" or "town center". These spaces are an artificial means of reconnecting residents with seemingly familiar characteristics utilizing such features

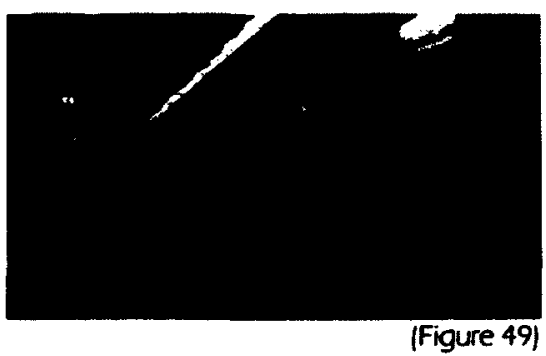

Main Street at the Waterford Retirement residence, Kingston Ontario.

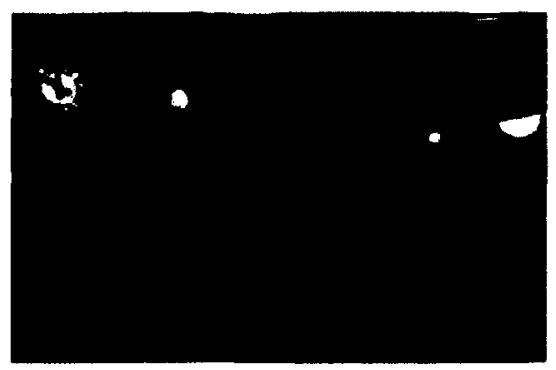

(Figure 50) Waveny care center, New Canaan as: windows, porches, siding, shingles, lampposts, street sign names etc. Although the "main street" concept has therapeutic intentions, it can also be perplexing for someone with dementia or $A D$ who may feel deceived to believe they are outside. The proposed design avoids this concept; each entertainment space will intertwine into the main circulation feature; amenities will include a theater, a library, a spa, a crafts and music room, a fitness and physiotherapy center, and a small chapel/meditation space. As previously mentioned by John Zeisel, art is an important element that can influence people living with $A D$ in a powerful way. Art experiences, such as the proposed program space of gallery, crafts and music room, will enable the residents to express their 
perceptions and evoke past memories. ${ }^{57}$ These spaces will, further, also allow the resident and their family to focus on something together, as opposed to each other. $^{58}$ To avoid the confusion of a single multipurpose room, each program will have its own room that will associate with different senses and experiences. Furthermore, some of these programs. such as, the theater, library, and chapel, will be reachable on various floors to encourage easy access, and thus, participation. Unlike most typical retirement and long term care facilities which have their entertainment district on the main floor or the basement, the 'main entertainment floor' of this proposal will be located on the second floor. This will allow the ByWard Market "lifestyle" to continue to exist under the AD care center.

\footnotetext{
57 John Zeisel, I'm Still here: A New Philosophy of Azzheimer's care, (New York: Penguin Group Ltd., 20091, 19.

58 John Zeisel, 19.
} 


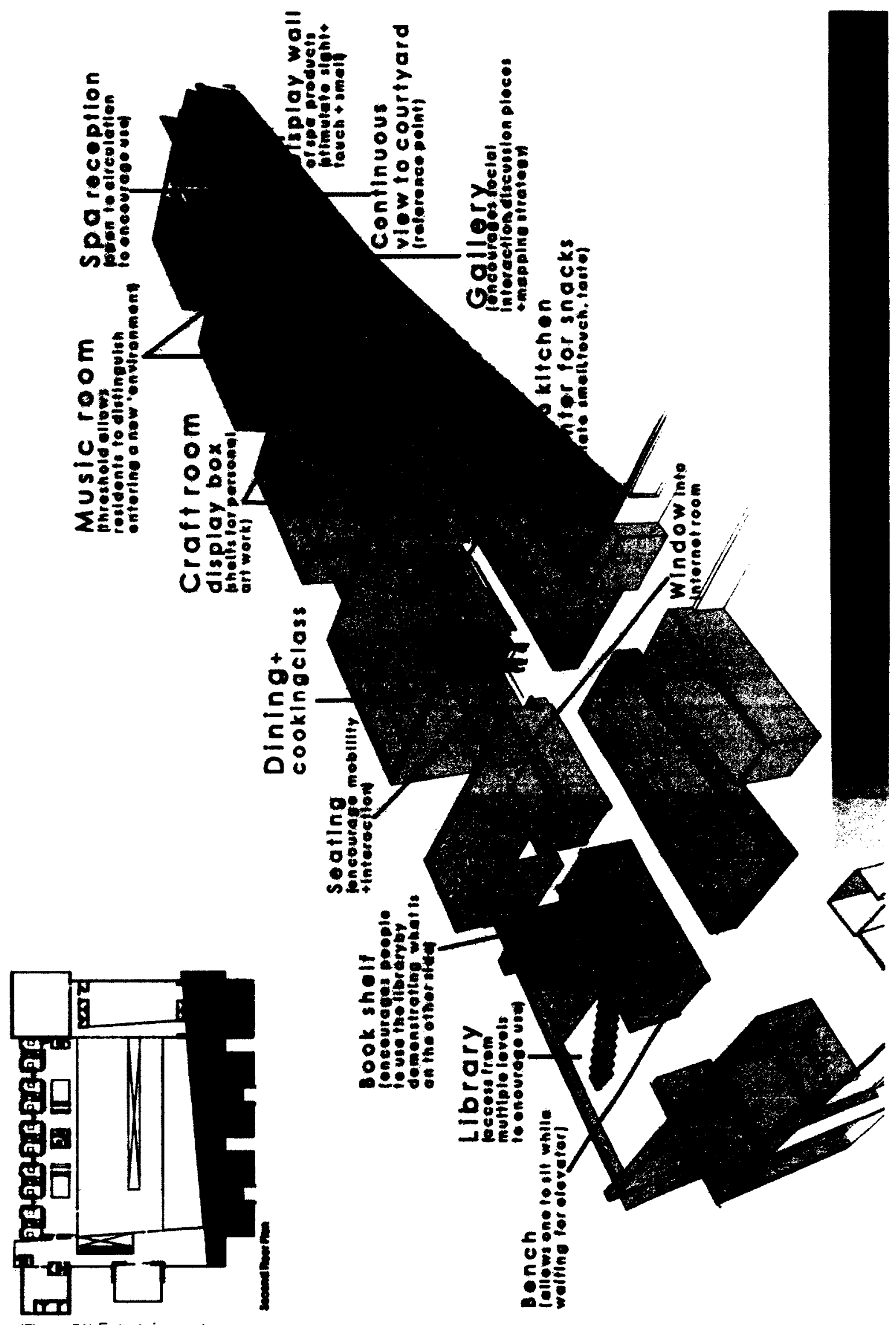




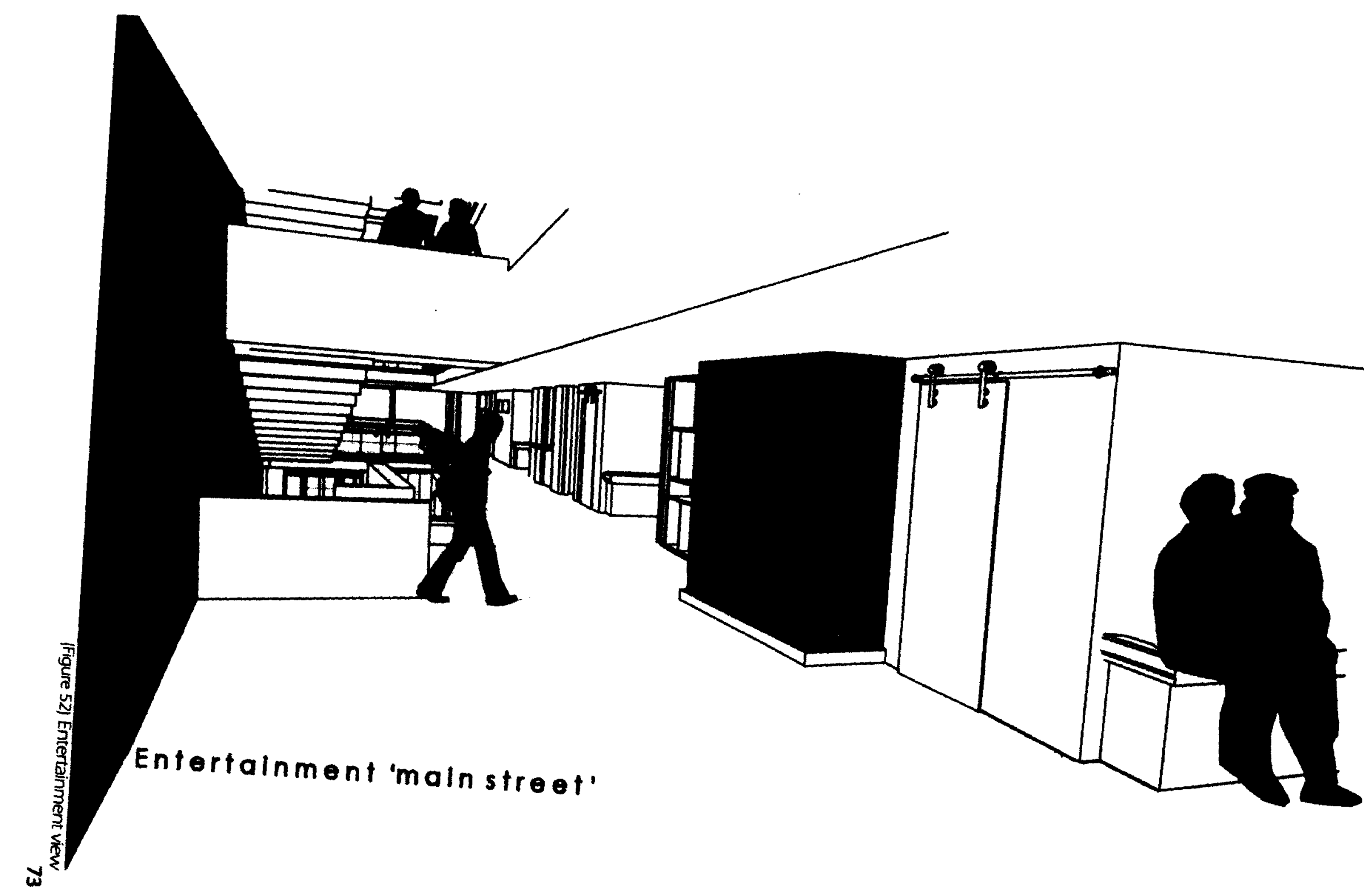




\subsection{Greenhouse}

It is common for many people living with dementia and $A D$ to remain in the same indoor environment for extended periods of time, especially during the winter. The large greenhouse will create an environment that can be enjoyed all year round for residents who find it to difficult to get out. The greenhouse will be designed similar to an exterior garden where there will be various pathways and shortcuts which will all lead to a central focal point. The greenhouse will allow residents to plant their own plants and take care of them every day if so desired. Caged birds and water features will also be incorporated to further provide an outdoor ambiance. The greenhouse provides another environment for family and resident to enjoy together.

\subsection{Wellness center}

The wellness center is located on the ground floor and will have street access; this will easily allow merchandise such as medication and therapeutic equipment to be brought into the wellness center. The wellness center will be beneficial for residents who are unable to conveniently leave the facility and may require seeing a doctor. Here, residents will be able to see a doctor as well as obtain prescriptions, physiotherapy, monthly check-ups etc. 


\subsection{Children's daycare}

The children's daycare program is located on grade level, and will be easily accessible from the street as well as the AD care center. This urban location is ideal for a daycare program as there are not many in the area and it will be a convenient location for families to drop off their children in close proximity to their work. The program will also coincide with the $A D$ care center, where $A D$ residents can read to the children, garden together and so forth. This will allow for many generations to come together. 

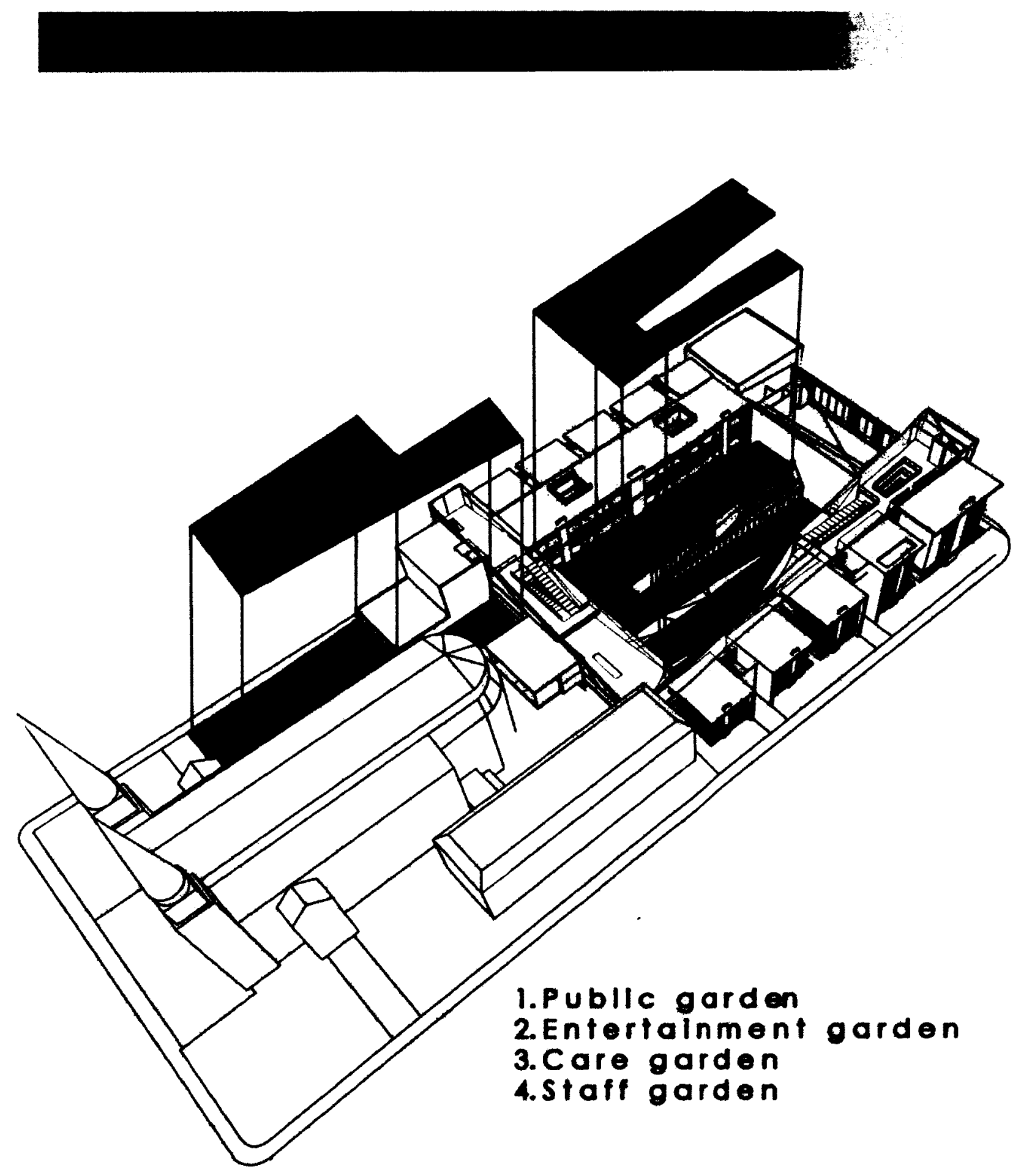

(Figure 53) Proposed four landscapes 


\subsection{Outdoor spaces}

The concept of a gently-sloped courtyard is that it can be seen from everywhere throughout the entire building. Moreover, a sloped landscape allows it to be linked to the second and third floor thus encouraging use by being easily accessible. It will act as a reference feature to help residents and $A D$ daycare program attendees to distinguish where they are located.

The exterior landscape will have four different themed gardens which will stimulate many senses.

1- Public garden

2- Entertainment garden [Mild Alzheimer's garden]

3- Care garden [Moderate Alzheimer's garden]

4 Staff garden

\section{Public garden}

The public garden is located on the ground level and will be dedicated mostly to the public; residents will also be able to enjoy this space with family member assistance. This courtyard will be an oasis, a place to escape from the busy metropolitan surrounding. The courtyard entry will not be obvious to locate since it will be surrounded by infrastructure on all four sides; however, once discovered would act as a hidden gem within the city. The surrounding walls will further act as shelter from the weather and noisy, fast-paced Market. The courtyard will offer various seating arrangements to allow people to have a lunch break, read a book or perhaps simply relax and enjoy the sun and picturesque views. The park will also include flower beds, a play structure and water 
features that could be enjoyed by all ages, such as young children frolicking, or the elderly enjoying the peaceful sound of water and children's laughter.

\section{Entertainment garden}

The entertainment garden will be accessible from the second floor, "the main floor". This space will include an amphitheatre to encourage the residents to be entertained while enjoying fresh air. This amphitheatre will also act as a focal and reference point for strolling residents. The amphitheatre will further provide seating arrangements of varying sizes to encourage social interactions for small and larger groups. The goal of this courtyard is to provide residents a sense of freedom alongside security in knowing that they can move throughout the garden without getting lost. This will be accomplished with visual cues such as water features, raised planters, artefacts, sundials, a screened porch, and wander loops, which all help to navigate the residents. As previously mentioned in Chapter 3, Design Strategies. this courtyard will also focus on daily tasks such as: gardening, hanging up clothes, bird watching, raking leaves. Furthermore, the garden will provide heat lamps, to allow residents to use the garden all year round.

\section{Care garden}

The care garden will be accessible from the third floor, and is designed particularly for those with progressive AD. This garden is carefully planned to provide residents with a sense of security and freedom. It will provide a terrace easily accessible for beds and 
wheelchairs. It will supply a simple garden layout so residents will not become disoriented or confused. It will incorporate bird feeders and pet areas as a therapeutic healing program. There will be no gates or locks which will help reduce the feeling of confinement. Furthermore, adequate lighting, from above as well as at wheelchair height will be used to compensate for those with vision impairment.

\section{Staff garden}

Most healthcare facilities provide staff members with a lounge which is seldom more than a small crowded dark room. This proposed design will dedicate a garden to employees who need a break from work and a place to relax and re-energize in the fresh outdoors. This garden will be located on the second floor near the service program and will provide seating for employees to, for example, eat lunch or play cards. It will also provide a ramp down to grade level, if they choose to go for a walk in the Market. 

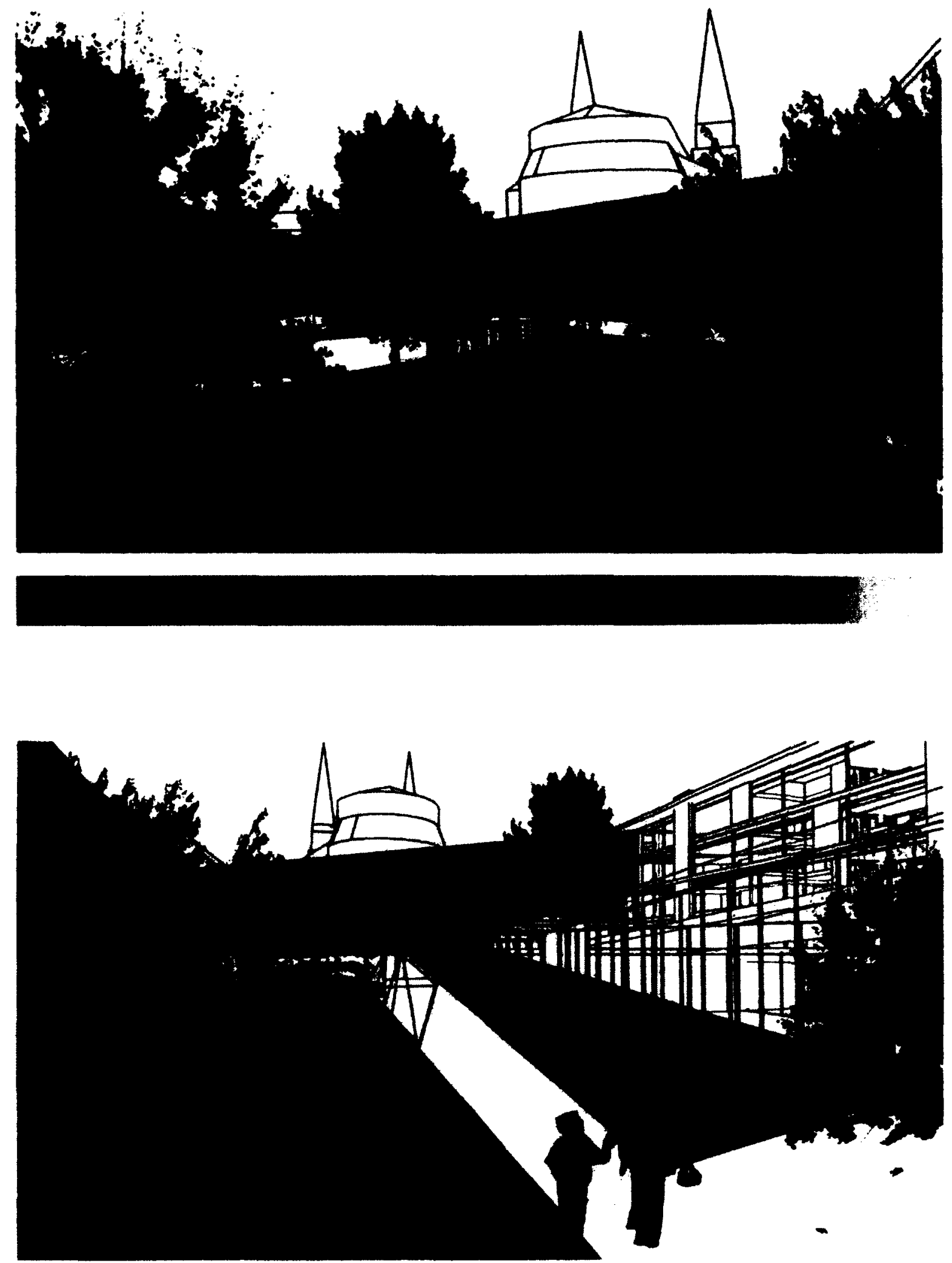


\section{Condusion:}

As the Baby Boom generation continues to grow older, healthcare facilities are increasingly in demand, especially for the population with $A D$ and dementia, as they require a specialized environment. Architects and designers are realising the importance of acknowledging and understanding the' challenges someone with $A D$ may face, such as vision, memory, mobility and hearing impairments. These common aging issues and moreover when entwined with $A D$ impede the user's interpretation of a space or environment and causes anxiety or fear. With increased awareness of the care center's users, architects and designers are able to better provide design strategies that will successfully accommodate people with $A D$. Well planned environments have been proven to be one of the most effective interventions to allow people with $A D$ to feel more independent, secure and to lead to an overall enhanced quality of life. ${ }^{59}$ As demonstrated in Chapter 4, $A D$ facilities have come a long way in just a short time. New healthcare environments avoid institutional settings and as a substitute, offer smaller, more familiar home-like spaces. Design strategies have abandoned the typical double loaded corridor, replaced by smaller "neighbourhood" clusters to help residents feel more comfortable and secure. Nurse stations are incorporated into workstations, more humane materials and finishes are being used, spaces include abundant natural light and well planned landscapes are created to promote a healthy, physical life while

\footnotetext{
59 Elizabeth Brawiey, Designing for Abheimer's disease. (New Jersey. John Wiley \& Sons, Inc., 19971. 307
} 
offering additional space for social gatherings. Based on existing precedents, research and, personal knowledge about $A D$, the intention of this thesis was to create the needed environments which would accommodate various individuals with AD. Family and human interaction is a large component of the proposed program; the well conceived architectural design will promote and encourage the importance of personal continued family engagement and provide amenities for residents to remain mentally active. The program goal was to design spaces that will allow the residents and visiting family and friends to be active together. Programs such as the theater, library, craft and music room, chapel, gallery, lounges, greenhouse, outdoor courtyards and the urban location allow for numerous activities that families and their loved one can engage in together. Each program is architecturally designed to allow residents to easily distinguish one space from another. Although I believe this proposal would be effective in enhancing residents' dignity, memories, mobility, and family interaction, there is no concrete evidence to prove this as a solution. Designing for $A D$ is very challenging as everyone progresses in their own unique way. therefore, architecture would need to respond personally to each resident; this would unfortunately not be realistic for a healthcare center. A solution may only be determined by research of trial and error of existing facilities and even then, there may never be one 'ultimate' spatial solution. 
Although there is currently no medical cure for people who suffer from AD and dementia:

The gift of design is a very special opportunity to contribute to people's lives, especially in healthcare environments and in moments of profound need. $^{60}$

60 Elizabeth Brawley. Designing for Alzheimer's disease. . (New Jersey. John Wiley \& Sons, Inc., 19971. 307 


\section{Bibliography}

\section{Books:}

Bal, Mieke, Lynne Cooke, Beatriz Colomina, Jerry Gorovoy, Christiane Terrisse. Danielle Tilkin, and Josef Helfenstein. Louise Bourgeois: Memory and Architecture. Madrid: Museo Nacional Centro De Arte Reina Sofia, 2000.

Bastea, Eleni. Memory and Architecture. New Mexico: The University of New Mexico Press, 2004.

Brawley, Elizabeth. Designing for Alzheimer's disease. .New Jersey: John Wiley \& Sons, Inc., 1997.

Gesler, Wilbert. Healing Places. New York: Rowman \& littlefield Publishers, Inc., 2003.

Hooyman, Nancy, and Asuman Kiyak. Social Gerontology: A Multidisciplinary Perspective. Boston: Alyn and Bacon Inc., 1999.

Kociol, Lori, and Myra Schiff. Alzheimer A Canadian Family Resource Guide. Toronto: McGraw-Hill Ryerson, 1989.

Mark Ashcraft, and Gabriel Radvansky, Cognition: Edition 5. New York: Prentice hall, 2009.

McKay, Donald. Sanctuary: a care centre for patients with Alzheimer disease. Waterloo: University of Waterloo Press, 1988.

McLachlan, Donald. Alzheimer A Canadian and Family Resource Guide. Toronto: Myra Schiff and Lori Kociol, 1989.

Perkins, Bradford, David Hoglund, Douglas King, and Eric Cohen. Building type basics for senior /iving. New Jersey: Wiley \& Sons, Inc, 2004.

Post, Stephen G. The Moral Challenge of Alzheimer Dlsease, Ethical issues from diagnosis to dying. Baltimore: The John Hopkins University Press, 2000.

Purves, Geoffrey. Primary Care Centres: Aguies to Health Care Design Second Edition. Burlington: Elsevier Ltd., 2009.

Sternberg. Esther. Healing Spaces: The Science of Place and Well-Being. United States of America: Harvard University Press, 2009.

Souren, Liduin, and Emile Franssen. Broken Connections: Origin and course, the world of the patient. Lisse: Taylor \& Francis, 1994.

Zeisel, John. I'm Still here: A New Philosophy of Alzheimer's Care. New York: Penguin Group Ltd., 2009. 
Journals:

Curtis, William. "Alzheimer's Respite Centre, Dublin, by Niall McLaughlin Architects." The Architect's Journal, the home of British architecture. (2011). http://unww.architectsjournal.co.uk/buildings/alzheimers-respite-centre-dublin-byniall-mclaughlin-architects/8611134.article (accessed January 12, 2012).

Deely, Beth, and Kristine Werlinich. Woodside Place: a personal care home for people with Alzheimer's disease." Aging. (1992).

Henry, Christopher. "Can design influence memory?:" Arch Daily. (2011). http://www.archdaily.com/184725/can-design-influence-memory/ (accessed January 30, 2012).

Reger, Beth. "Alzheimer's Disease: A Brief History and Avenues for Current Research." Journal of Young Investigators. 6. no. 2 (2002). http://unw.jyi.org/volumes/volume6/issue2/features/reger.html (accessed Dec, 19 $2011 \%$.

Shabahangi. Nader. "The Poetics of Aging and Dementia." Journal of Humanistic Psychology April 2010. 50. (2009): 187-196.

\section{Websites:}

Alzheimer's disease Research, "A history of Alzheimer's Disease." Last modified 01/10/12. Accessed January 4, 2011. http://umw.ahaf.org/alzheimers/about/.

Alzheimer's Society Canada, "Rising Tide: The Impact of Dementia on Canada." Last modified 12/01/11. Accessed March 2, 2012. http://umw.alzheimer.ca/en/Aboutdementia/Alzheimer-s-disease/What-is-Alzheimer-s-disease.

Alzheimer's Society Canada, "What is Alzheimer's disease:" Last modified 11/29/11. Accessed March 27, 2012. http://mww.alzheimer.ca/en/About-dementia/Alzheimers-disease/What-is-Alzheimer-s-disease.

Canada's historic places, "Notre-Dame Roman Catholic Basilica National Historic Site of Canada." Accessed March 3, 2012. http://www.historicplaces.ca/en/rep-reg/placelieu.aspx?id=12135\&pid=0.

Cornwall, Ontario Canada, "About Glen Stor Dun Lodge." Last modified 2009. Accessed February 30, 2012. http://www.cornwall.ca/en/glenstordunlodge/AboutGSD.asp.

Ottawa, "Cultural Heritage Value or Interest of Lower Lorne Avenue." Last modified 2012. Accessed February 2, 2012. http://uww.ottawa.ca/en/city_hall/planningprojectsreports/planning/built_heritage /lorne/description/index.htmihttp://www.ottawa.ca/en/city_hall/planningprojectsre ports/planning/built_heritage/lorne/description/index.html.

The hearing Foundation of Canada, "Statistics." Last modified 2010. Accessed February 4, 2012. http://mww.thfc.ca/cms/en/KeyStatistics/KeyStatistics.aspx?menuid=. 


\section{Illustrations:}

3 (Figure 1) Illustration comparing a healthy brain to a person who has AD [http://wnw.alz.org/braintour/healthy_vs_alzheimers.asp]

17 (Figure 2) Waterford retirement home, Kingston Ontario [by author]

25 (Figure 3) Alzheimer's Respite Centre in Dublin, Ireland [http://mww.irisharchitectureawards.ie/annualawards/2010/alzheimers_respite_centre/]

26 (Figure 4) Continuous view of exterior garden [http://mww.architectsjournal.co.uk/buildings/alzheimers-respite-centre-dublin-byniall-mclaughlin-architects/86/1134.article]

26 (Figure 5) Remaining $18^{\text {th }}$ Century walled kitchen [http://unw.niallmclaughlin.com/01 10_l.html]

26 (Figure 6) One of many courtyards [http://mww.irisharchitectureawards.ie/annualawards/2010/alzheimers_respite_centre/]

26 (Figure 7) Coloured bedroom doors and natural lighting from above [http://www.niallmclaughlin.com/0110_7.html]

27 (Figure 8) Floor Plan of Alzheimer's Respite Centre [http://www.architizer.com/en_us/projects/pictures/alzheimers-respitecentre/7416/53612/]

29 (Figure 9) Glen Stor Dun Lodge, Cornwall, ON [http://mww.cornwall.ca/en/glenstordunlodge/GSDPhotos.asp]

30 (Figure 10) "Main Street" on ground level at Glen Stor Dun Lodge [by author]

30 (Figure 11) Ledge and memory photo frame [by author]

30 (Figure 12) Long double loaded corridor [by author]

30 (Figure 13) Plan of Glen Stor Dun Lodge (demonstrates a lounge at the end of the corridor [by author]

32 (Figure 14) Woodside Place, Oakmont, Pennsylvania [http://mww.architectureweek.com/2004/1215/design_3-2.html]

33 (Figure 15) Dutch door [http://mww.architectureweek.com/2004/1215/design_3-2.html]

34 (Figure 16) Woodside Place, concept floor Plan [http://mww.architectureweek.com/2004/1215/design_3-2.html + author] 
36 (Figure 17) Aerial plan of LeBreton Flats [http://maps.google.ca/]

38 (Figure 18) Aerial view of Carleton University site [http://maps.google.ca/]

40 (Figure 19) Chosen Site, and its Context [http://maps.google.ca/]

41 (Figure 20) View from St. Patrick St. (existing houses on the right) [by author]

41 (Figure 21) Corner view from St. Patrick st. and Parent Ave. [by author]

41 (Figure 22) Back view of site, from Parent Ave. [by author]

41 (Figure 23) View from Parent Ave. with Church and National Art Gallery in the background [by author]

43 (Figure 24) ByWard courtyard study [http://maps.google.ca/]

47 (Figure 25) Inspired vertical feature [http://Mww.apartmenttherapy.com/nooutdoor-space-an-indoor-roc-147532]

44 (Figure 26) Process work - Option A and B [by author]

45 (Figure 27) Process work - Option C and D [by author]

46 (Figure 28) Process work - Option E [by author]

47 (Figure 29) Process work - Option F [by author]

50 (Figure 30) Proposed site plan [by author]

51 (Figure 31) Proposed program [by author]

52 (Figure 32) Proposed elevations [by author]

53 (Figure 33) Proposed section [by author]

54 (Figure 34) Below grade floor plan [by author]

55 (Figure 35) Ground floor plan [by author]

56 (Figure 36) Second floor plan

57 (Figure 37) Third floor plan [by author]

58 (Figure 38) Fourth floor plan [by author]

59 (Figure 39) Fifth floor plan [by author]

60 (Figure 40) Street view [by author] 
61 (Figure 41) Street view [by author]

62 [Figure 42) Lobby view + light well and circulation view [by author]

63 (Figure 43) Preliminary room layout [by author]

64 (Figure 44) Room layout sketches [by author]

65 (Figure 45) Proposed room layout and 'pod' view [by author]

66 (Figure 46) Residence 'pod' axo [by author]

67 (Figure 47) Proposed vertical elements [by author]

69 (Figure 48) Proposed circulation element [by author]

70 (Figure 49) "Main street" at the Waterford, Retirement residence, Kingston Ontario. [by author]

70 (Figure 50) Waveny care center, New Canaan [Building type basics for senior living. p. 63]

72 (Figure 51) Entertainment axo [by author]

73 (Figure 52) Entertainment view [by author]

76 (Figure 53) Proposed four landscapes [by author]

80 TFigure 54) Courtyard views [by author] 
